\title{
EVERYDAY TALK: PERPETUATING CULTURES OF SEXUAL VIOLENCE ON COLLEGE CAMPUSES
}

by

Sara Collins

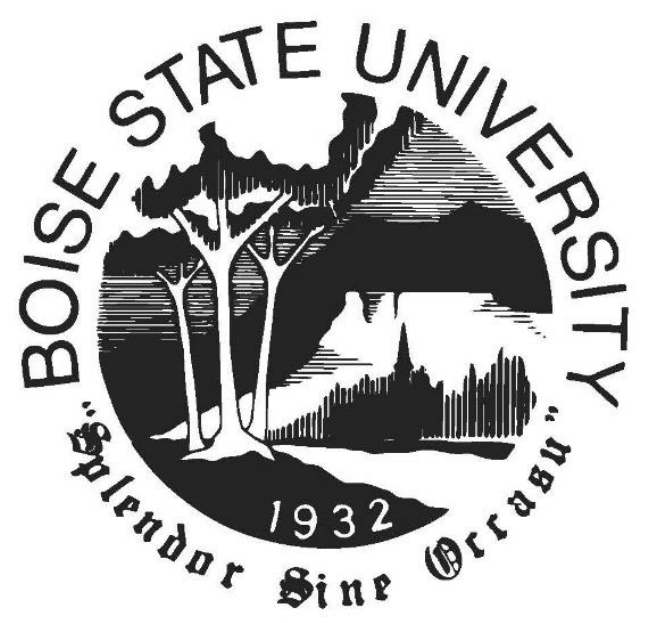

\author{
A thesis \\ submitted in partial fulfillment \\ of the requirements for the degree of \\ Master of Arts in Communication \\ Boise State University
}

August 2019 
(C) 2019

Sara Collins

ALL RIGHTS RESERVED 


\title{
BOISE STATE UNIVERSITY GRADUATE COLLEGE
}

\section{DEFENSE COMMITTEE AND FINAL READING APPROVALS}

\author{
of the thesis submitted by
}

Sara Collins

Thesis Title: Everyday Talk: Perpetuating Cultures of Sexual Violence on College Campuses

Date of Final Oral Examination: $\quad 23$ April 2019

The following individuals read and discussed the thesis submitted by student Sara Collins and they evaluated her presentation and response to questions during the final oral examination. They found that the student passed the final oral examination.

John G. McClellan, Ph.D. Chair, Supervisory Committee

Christina L. Ivey, Ph.D. Member, Supervisory Committee

Rulon Wood, Ph.D. Member, Supervisory Committee

The final reading approval of the thesis was granted by John G. McClellan, Ph.D., Chair of the Supervisory Committee. The thesis was approved by the Graduate College. 


\section{ACKNOWLEDGEMENTS}

I would like to express my deep gratitude to friends, family, and my committee for their support in completing this research. Thank you to Andrew for continual support when I hit walls or barriers, and cheering me on in my successes. Thank you to Dr. McClellan, for advice, guidance, and a listening ear throughout not only the process of completing this thesis but throughout my journey of graduate school. Finally, thank you to my parents and my Grandmother for their support, encouragement, and willingness to learn alongside me throughout my study. 


\begin{abstract}
While sexual violence on college campuses has always been present, recently, there has been heightened interest in ways that individuals can resist against this problematic and harmful culture. This study employs a communicative perspective grounded in social construction and relationships between power, language, and subjectivity to gain insights into the everyday talk that perpetuates rape culture. Specifically, four focus groups were conducted to understand how college students talk about dating, relationships, and sex. Qualitative analysis of the focus group transcripts revealed how women and men conceptualize the process of dating and critical analysis reveals how the talk about relationships and sex contributed to imbalances of power and marginalization of women-perpetuating rape culture on college campuses. I offer a discussion linking the findings of this study to social construction and research on power, language, and subjectivity, and conclude with recommendations for future research exploring everyday language use and issues associated with sexual violence on college campuses.
\end{abstract}




\section{TABLE OF CONTENTS}

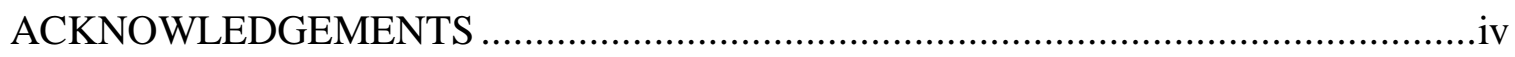

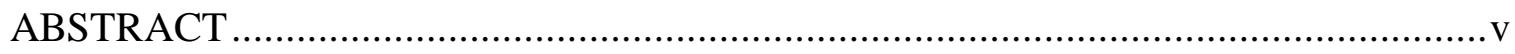

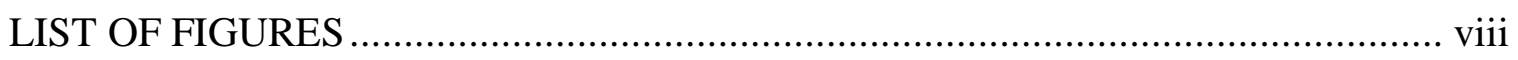

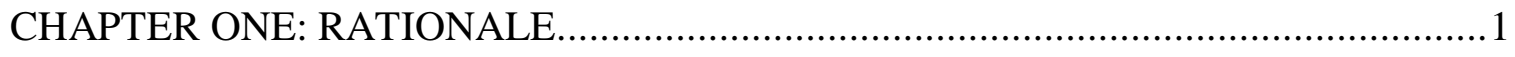

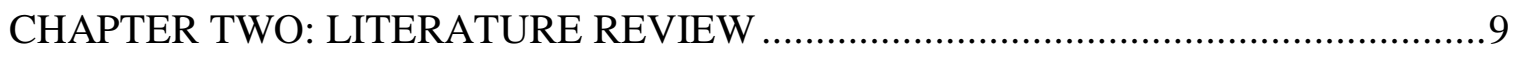

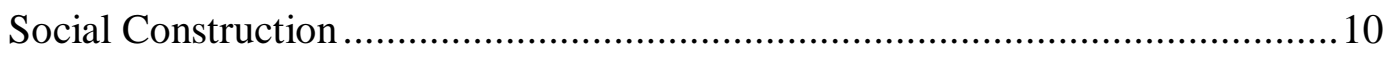

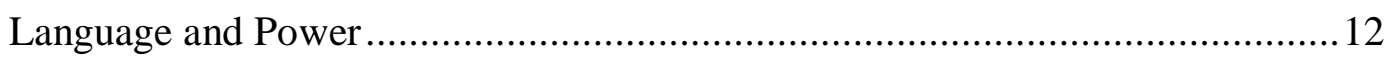

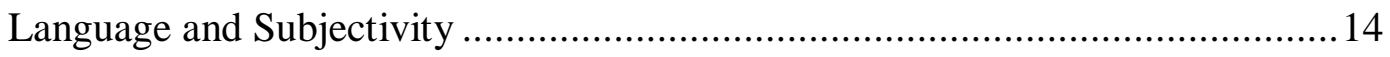

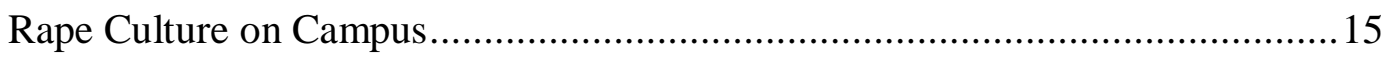

Rape Culture as an Outcome of Language ........................................................19

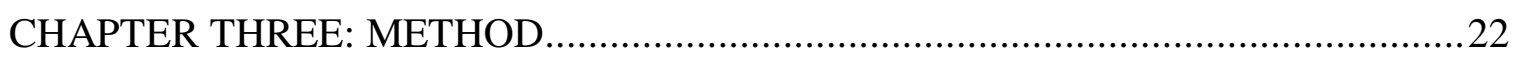

Qualitative Research and Critical Analysis .....................................................22

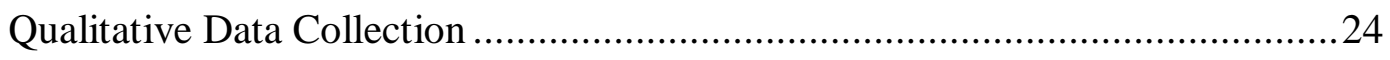

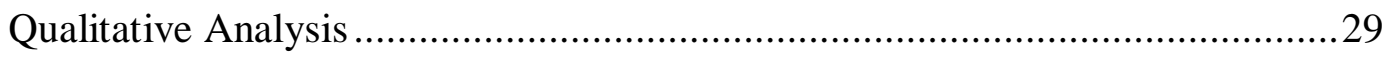

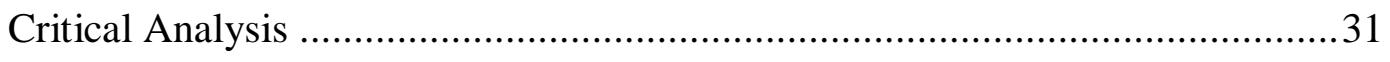

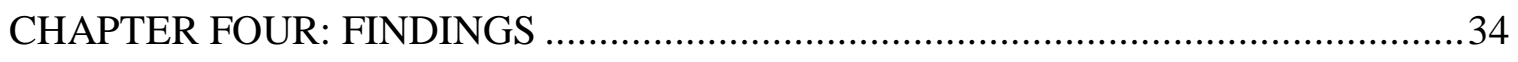

The Ways College Students Talk about Dating, Relationships, and Sex...............34

The Language Used by Women: Describing the Dating Process ...............34

The Language Used by Men: Describing the Dating Process ...................42 
How College Students Talk about Dating, Relationships and Sex

Critiquing the Ways College Students Talk about Dating, Relationships, and

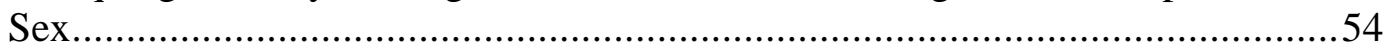

Critical Analysis of Women's Language .........................................54

Critical Analysis of Men's Language ............................................60

How Talk Perpetuates Rape Culture on College Campus .....................66

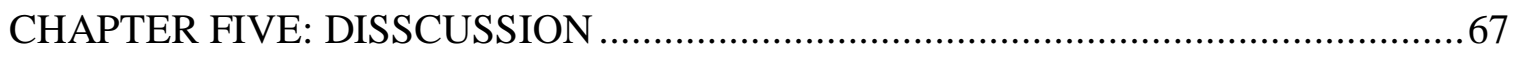

Recommendations ............................................................................. 72

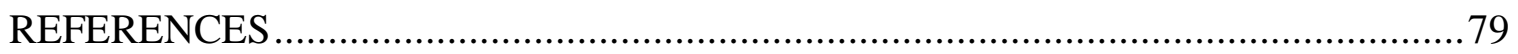




\section{LIST OF FIGURES}

Figure 1. Process of dating as described by women. This diagram emerged as a result from the transcriptions of the focus groups.....................................50

Figure 2. Process of dating as described by men. This diagram emerged as a result from the transcriptions of the focus groups. ............................................52 


\section{CHAPTER ONE: RATIONALE}

As a woman who has watched friends, family, and peers be impacted by sexual assault, I came to notice how the ways we talk about these experiences and the openness we feel in our ability to talk about these experiences is and has always been, complex. Through each phase of my life, sexual assault has presented itself in different ways, and each time the ways we needed to talk about it were not available or supported.

During high school, a girlfriend and I went to a party at a friend's house. After a long evening, we decided to spend the night and slept in separate rooms. In the morning, when she came out of the room she slept in with one of our close friends, she asked, "does it count as losing my virginity if I did not want to do it?"

During college, I was in a sorority. While at one of our chapter retreats, I facilitated 'Cross the Line,' an activity with 150 sisters that was intended to bring people together by sharing life experiences. When questions are posed, you step forward and cross over a line if you agree or have experienced what was described. When the women were asked if they had experienced some form of sexual assault, approximately threefourths of the room crossed the line. As I listened to the stories of my sisters, I heard them blaming themselves and sharing their feelings of loneliness and hopelessness. I learned that some transferred schools, seeking safer environments because of their experiences and others suffered in silence throughout their lives.

During graduate school, I sat on the bench at a softball game and listened to a woman defend her best friend who had raped one of their own friends just a week before. 
"If you only knew him like I did, you would understand. It wasn't like that," she said. These and many other stories prompted my interest in studying how the ways people talk about sex and relationships contributes to an environment that perpetuates sexual violence.

Through each of these experiences, and many others, I began to understand the ways my friends, my sisters, and even perpetrators talked about sexual assault in particularly problematic ways. As I reflect on my collegiate career, I think about the 20year-old woman who thought she had agency and freedom over her sexuality, who prided herself in her ability to choose and to not choose and to own her body and its actions. However, once I began understanding the notion of social construction more deeply, I began to better understand my position in the discourse and began to feel less and less of that agency and freedom I so greatly desired. However, it was through greater understanding of these issues of language and the constitution of reality that I developed a sense of commitment to not just understand how change can be made but spread that knowledge, even in small conversations, with hope other women and men would fight back and fight against the ways people talked about women, sex, and relationships that had pushed me, my friends, and many other women, down for so long.

For this thesis study, I am researching the everyday language that perpetuates cultures of sexual violence on college campuses. More specifically, I am interested in understanding how college students talk in subtle and taken-for-granted ways that contribute to problematic systems of meaning for women on college campuses. While this language might not be intentional, the common ways of using language about sex and relationships creates meanings that can marginalize. For instance, when college 
students talk about sex and women they may generate meanings that position women in particular ways and thus, participate unknowingly in discourses that perpetuate hurtful ways of knowing women and sex. This common language perpetuates cultures of sexual violence and creates implications for what it means for a women's individual identity and experience. For many, these conversations are taken for granted and inconsequential but for others they become detrimentally hurtful when heard repeatedly over time.

The repetition of hurtful comments can contribute to cultures of sexual violence and marginalization of women. Ultimately, these comments are perpetuating a culture that was unknowingly being fueled in the first place, but are impactful nonetheless. The purpose of this study is to examine how college students talk about relationships to gain deeper understanding of the language that unknowingly perpetuates rape culture on college campuses. Rape culture is a setting in which rape, and overall sexual violence, is normalized by the societal attitudes surrounding gender and sexuality (Marshall University, 2018). In environments fostering rape culture, sexual violence against women is not only normalized but often excused and perpetuated through the use of language that objectifies women's bodies and glamorizes sexual violence (Marshall University, 2018). This language creates spaces that allow for the disregard of women's rights and safety, and eliminates room for individuals who have been victim of these actions. It is important to note that definitions that currently lie within research and laws can be particularly challenging in that, rape and rape culture is not exclusive to women. All identities can become victims to rape and rape culture, and while for purposes of this study, I will operate out of the definitions that are currently available, it is important to note and 
recognize that all identifies are affected by this epidemic and therefore, this is not just a women's problem but a problem for all.

Sexual assault is an increasing problem on college campuses, bringing both short term and long-term effects to many victims. Health problems such as depression, anxiety, eating disorders, post-traumatic stress disorder, and suicidal ideation occur amongst many college students, as well as physical injury, sexually transmitted infections, and chronic illness (Fedina, Homes, \& Backes, 2016). College students who have been sexually assaulted have a higher likelihood of engaging in binge drinking, drug use, and lowered academic achievement (Fedina, Homes, \& Backes, 2016). Additionally, a student who has been sexually assaulted will also have a higher risk of revictimization achievement (Fedina, Homes, \& Backes, 2016). Studies in this area matter because this affects the livelihood of students on college campuses.

In this study, I aim to discover the ways college students talk about sex, dating, and relationships that contribute to the perpetuation of rape culture. Embracing social construction theory and a concern for issues of power and language, I aim to explore how language creates realities, and ways of knowing the self, that reconstitute rape culture (Berger \& Luckmann, 1966; Deetz, 1992; Weedon, 1987). If rape culture is to be understood, looking to the ways in which it is perpetuated, specifically through language used in everyday talk, must be identified. By researching the ways college students' everyday talk contributes to rape culture, I aim to reveal the complex relationship between communication, power, and identity and offer insights that might help efforts to enhance university environments for women. The findings of this study can help educators and campus administrators and others interested in improving educational 
programs on sex, sexual health, and sexual assault on campuses by targeting the language used and seek alternative vocabularies for talking about sex and relationships. If educational programs focused on rape culture placed more focus on how the use of takenfor-granted language perpetuates rape culture, such training would equip students with a way to recognize the power of everyday language use and seek ways to change the ways we talk about sex, dating, and relationships as part of putting a halt to perpetuating rape culture on campuses.

More specifically, many college students come onto a campus without having a substantial amount of background in language as it pertains to sex. It is crucial for students to know how to communicate in a safe and effective way about sex, sexual relationships, and rape in order to avoid consequences such as those mentioned above. This study has the potential to contribute to our understanding of how we educate youth on gender and sexuality. Research has identified a clear need for school-based programs that address rape, and where they have been integrated, success has been found (Fey \& Medway, 2006). For instance, one program implemented in rural South Carolina, found that integrating rape education programs into schools for students transitioning into high school, lowered their rape myth acceptance likelihood significantly compared to the rape myth acceptance prior to the programing (Fey \& Medway, 2006). If more information was discovered about the ways students talk, it could potentially lead to insights similar to this program, which specifically brought to the students' attention the importance of healthy relationships and honesty (Fey \& Medway, 2006). Furthermore, should these topics be integrated into high school level health classrooms, students might be better prepared when entering college and better able to aid in lower assault numbers on college 
campuses. If we are able to find places to shift the conversations and re-address the language used when we talk about rape we may help reduce the number of sexual assaults on campus. While we can't be sure the direction education would take knowing the impact of language on rape culture, it is clear that college campuses have a need for change that goes deeper than our everyday conversations and calls for a larger change in the systemic ways we have learned to communicate about rape and sex.

Unfortunately, at the point when college students come to campus, they have passed the stage in which they would have been most vulnerable to molding and shaping their minds when it comes to how to talk about sex, dating, and relationships in healthy ways. While this study acknowledges that a great avenue of learning about this topic is through educational institutions themselves, I am going to look specifically at the way college students talk with one another and the influence that dialogue has in the perpetuation of rape culture.

In order for things to change, it must be understood how rape culture is manifested in everyday language to reveal the problem and learn if it is possible to communicate in different ways that can create more safe and inclusive environments (especially on college campuses). Discursive openings and alternative ways to talk about sex and women can generate new realities that lead to safer cultures for women and open dialogue circulating these topics. To better understand the perpetuation of rape culture, studying language use is important. For example, in a study by Fedina, Holmes, and Backes (2013), they differentiate individual's experiences as "completed rape" or "attempted rape." The words used to define the individuals experience can change the way they make sense of their personal narrative. In this instance, the use of "completed" 
versus "attempted" could insinuate that the individual who experiences attempted rape didn't live the full experience, so perhaps they can't know the full extent of trauma that rape brings. These small differences in words make up the big picture of why our culture struggles to talk about sex and rape, and how the language we do use everyday perpetuates it at the same time. This form of meaning making comes from institutionalized systems that have worked for years and years to create meanings about society and ourselves (Deetz, 1992; Weedon, 1987). Often, we do not find opportunities or chances to look at how those systems have affected our definitions of ourselves and society, and our understanding of those, and my aim of this study is to critically examine the everyday language college students use to talk about dating and sex to reveal the taken for granted, yet institutionalized, systems of meaning that have been established that perpetuate rape culture in the United States. My hope is that such as study can spark interest among individuals to reconsider the ways they talk by realizing how every day, often mundane, ways of talking solidify problematic ways of knowing women and contribute to issues of sexual violence being tolerated and justified at college.

In the next chapter, I will review relevant research grounding this study by discussing literature on social construction, language and power, the relationship between language and subjectivity, and rape culture. Embracing these ideas, I provide an argument for how everyday language use about dating and sex contributes to rape culture, and will present the guiding questions for this research. In the fourth chapter, I will present the methods of research I have used to respond to my research questions. I will discuss my commitment to qualitative approaches and explain how social construction informs the interpretive methodology I employed for this research study. I will then 
present the qualitative methods I used for data collection through focus groups and review the qualitative and critical methods I used for data analysis. In the final chapter, I review the findings of the study, and discuss the overall implications and recommendations for future studies within this field. 


\section{CHAPTER TWO: LITERATURE REVIEW}

There is an abundance of literature on rape culture as it relates to college campuses (see Barnett, Hale, \& Sligar, 2017; McMahon, 2010; Reling, Barton, Becker, \& Valisk, 2018; Haugen, Rieck, Salter, \& Phillips, 2017; Lee, Pomeroy, Yoo, \& Rheinboldt, 2005; Marshall University, 2018; Wiersma-Mosley, Jozkowski, \& Martinez, 2016; Reling, Barton, Becker, \& Valasik, 2017). Researchers interested in rape culture have explored why it happens and what perpetuates it to reveal the subtle ways it is embedded into our everyday life. Understanding the way meaning is made when it comes to rape culture is important to the wellbeing of individuals living on college campuses, and important to the wellbeing of societies. More specifically, a better understanding of how language contributes to the marginalization of people and how language can also be used to create safer conversations about sex and relationships is needed if we want to seek alternatives to rape culture. In this chapter I embrace a strong communication perspective, and review the theory of social construction as a foundational concept for this study. I continue, however, with a review of the relationship between language, power, and subjectivity to develop the notion that everyday language constitutes not only social realities but positions from which to experience those realties. I then review contemporary literature on rape culture on college campuses. Combined, I develop an argument for how subtle, everyday ways of talking about dating and sex constitute rape culture leading to problematic environments for women on college campuses. I conclude 
this chapter with a review of the guiding questions for this study and transition to the methods I have used to conduct the study.

\section{Social Construction}

At the core of social constructionism, is the idea that over time, individuals who interact in a social system, create concepts and representations of each other's actions. Through communicative practices that are ongoing, these concepts and representations become habitualzed as normative roles that can be played out by actors in relation to one another. When these roles are made available to individuals and groups within a society to take on and play out, the reciprocal interactions are then institutionalized (Berger \& Luckmann, 1966). In the process of institutionalization, knowledge and people's conceptions (and beliefs) of reality become embedded in the institutional fabric of society. Reality is therefore socially constructed (Berger \& Luckmann, 1966). Individuals embracing social constructionism believe the role of humans in actively using symbolic resources to objectify, circulate, and interpret the meaningfulness of their environments and their existence. In this way, meaningfulness is not passive but is dependent on human interactions to respond to the world and create cultural meaning (Lindlof \& Taylor, 2011). This view embraces how symbols, language, discourse, and media operate in the process of creating institutionalized influences on culture, and specifically, individuals. Institutionalization occurs when socially constructed meanings become taken for granted through habits and established in behavioral norms (Berger \& Luckmann, 1966). These habits and norms are formed through mutual observation and understanding of "the way things are." These habits and norms can positively impact individuals in the sense that it reduces uncertainty, and can clear headspace and time of decision making (Berger 
\& Luckmann, 1966). While habits and norms that are played out in everyday life seem to have little or no impact, the idea of habitualization as a social construct can have implications when the view and scope of behavior and choices are narrowed. For example, many social constructs are held in place due to the excuse that "things have always been this way," or, "it has always worked, so why change it." Using justifications for why things are done the way they are, when they are done in thoughtless ways, is a result of social arrangements in which the habit is developed and enforced (Deetz, 1992). The way experiences are perceived is directed, inherently, by the institutionalized practices of society and the culture around an individual (Deetz, 1992). These narrow ways of thinking may be harmful to an individual when they construct a world that is harmful and violent, such as when rape culture is perpetuated in everyday language.

All words, actions, and thoughts of an individual are subject to habitualization (Berger \& Luckmann, 1966). Anything done repeatedly or frequently, over time, becomes habit and creates a pattern of speech, action, or thought. These habitualized actions become meaningful when they are embedded into routine and guide the decision an individual makes in the future, due to the pattern of behavior (Berger \& Luckmann, 1966). In a more specific sense, the language individuals hear each day becomes a part of the pattern of language they know. If individuals repeatedly hear specific words, it is more likely they become a part of their own frequently used language as well. Habitualization becomes problematic when it limits the choices of the individual (Berger \& Luckmann, 1966). There could be a vast variety of options to use when it comes to, for example, word choice in a conversation, however the bank of words an individual is frequently spoken to or uses limits the immediate options they will consider when 
engaging in dialogue. Certainly, it does provide the individual with direction and free them from too many decisions, giving psychological relief from having to know all options (Berger \& Luckmann, 1966). It provides a stable background that allows for more energy for deliberation and innovation (Berger \& Luckmann, 1966). However, it does, unfortunately, provide pre-definitions to situations and interactions, creating a narrow mindset with limited choice (Berger \& Luckmann, 1966). Those exploring the limitations of choice often focus on the interrelationship between language and power.

\section{Language and Power}

Language plays an important role in the social construction of everyday reality. Language links commonsense knowledge with meaning and transcends the reality of everyday life altogether. However, as language use establishes and institutionalizes particular realities (Berger \& Luckmann, 1966) it also establishes power relations. The way individuals engage in this use of language, however, is rooted in the social practices, forms of subjectivity and power relations that are connected between them (Weedon, 1987). Often referred to by the term "discourse," these everyday ways of talking cannot exist in simple relations to power and powerlessness but are elements in the operating field of force relations (Weedon, 1987). These force relations establish relations of power which take specific forms of in groups, such as, relations of class, race, gender, religion, and age. Furthermore, the site of these relations are the social institutions in which subjectivities are constituted and social control exercised (Weedon, 1987). This means that when discourse is exercised, power is inherent in some form.

From this perspective, power is a relation. Power is not held or wielded; instead, it is dynamic of control and compliance. In discourses power is exercised in ways that 
allow the governing and constituting of individuals (Weedon, 1987). In other words, as people talk, they reproduce particular ways of knowing the world that establish relations among people (Weedon, 1987). For example, looking to rape as an epidemic allows for the evaluation of power constructs constituting the issue at hand, however, until recently, rape has been evaluated on an incident basis, making it more difficult to identify the power influence involved. Power also structures relations between subjects both across and within different discourses (Weedon, 1987). For example, some forms of sexual assault were not previously recognized by the law as rape or even assault. For individuals who were victim to this, they were unable to step into the discourse around sexual assault and find justice from their attacks. Victims of assault were forced to find alternate avenues to share their experiences and voices, until the law was able to recognize more forms of sexual assault. In this way the ways sexual assault was defined structured relations among people. These power structures worked to leave certain populations out of discourse, pushing them to find these alternate routes of communication to be able to be heard.

This connection between language and power is often discussed in terms of the politics embedded in discursive practices. From this perspective, everyday experiences are inherently political, due to the institutional practices that are produced and in turn, reproduce both power differences and power advantages (Deetz, 1992). If the experiences of everyday life are inherently political, the language used in and to describe everyday experiences must be political too. Language makes experiences accessible to all within the linguistic community, serving as a basis to create meaning of experiences and as an instrument to collective knowledge among individuals (Deetz, 1992). Language is an 
institutional practice, and as such, its constitutive role must be understood as one too (Deetz, 1992). The way individuals' subjectivity is defined and created through language, situating some individuals at one level, and some at another, creates a power relations that are inherently embedded into society. From this perspective, the ways individuals talk and engage in discourse establishes relations of power, often without ever knowing.

\section{Language and Subjectivity}

Language not only establishes relations of power but constitutes individual subjectivity. Language use shapes the way one makes sense of the world and more importantly, themselves (Weedon, 1987). In this way, language constitutes social organization, social meanings, power, and individual consciousness. Language is the site where actual and possible forms of social organization and their consequences are defined and contested (Weedon, 1987). Individual expressions in everyday life create significant meanings, making it essential to understand the ways that language creates individual reality. While interaction through language is most often experienced face-toface, the origins of expressed words and meanings can be very detached from that of specific experience (Berger \& Luckmann, 1966). This means the way individuals exchange language as a symbol and develop shared meanings, it creates room for meaning to become taken for granted, and often hurtful, when the meaning to one individual is not the same to another.

Language in itself can be analyzed in very political means. Many people want to divide personal and political, but communication scholars argue, the personal is political, because the personal encompasses the nature of the individual and their experience of the world, including both experiences that are innate as well as those that are socially aquired 
(Weedon, 1987). Individuals cannot separate the political and personal, when the political has informed their experiences and the two become intertwined. Language and experiences then, create reality for an individual, and in turn, create meaning in their everyday life.

So how can the way language influences and creates an individual's reality be negative? When certain perceptions, or shared meanings in a society, become protected as common sense. The social order of these perceptions effects legitimate knowledge and personal identities that are invested in them (Deetz, 1992). Subjectivity is produced in a whole range of discursive practices, including economic, social, and political, the meanings of which are a constant site of struggle over power. Language is not the expression of unique individuality; it constructs the individual's subjectivity in ways which are socially specified, creating accepted language and meanings for an individual's everyday life (Weedon, 1987).

\section{Rape Culture on Campus}

Literature and government programs define rape as, "the penetration, no matter how slight, of the vagina or anus, with any body part or object, or oral penetration by a sex organ of another person, without consent of the victim," (Wiersma-Mosley, Jozkowski, \& Martinez, 2016; FBI, 2013). As one of the most severe and underreported crimes in the U.S., one out of seven women will be raped in her life according to the National Violence Against Women Survey (Lee, Pomeroy, Yoo, \& Rheinboldt, 2005; Wiersma-Mosley, Jozkowski, \& Martinez, 2017; Reling, Barton, Becker, \& Valasik, 2017). Even more prevalent is the higher risk factor for women between the ages of 16 and 24, who are four more times likely to experience rape than any other age group of 
women. And $50 \%$ of college-aged women have experienced some form of sexual victimization and 1 out of 4 have been victims of rape (Lee, Pomeroy, Yoo, \& Rheinboldt, 2005; Wiersma-Mosley, Jozkowski, \& Martinez, 2016; Reling, Barton, Becker, \& Valasik, 2017).

Common factors attributed to a higher risk of rape to college campuses include presence of alcohol or drugs, Greek community presence, athletic team presence, type of college (public v. private), and even the amount of tuition (Wiersma-Mosley, Jozkowski, \& Martinez, 2016). Specifically, fraternity and athlete groups are at a higher risk for sexual assault perpetration. These groups are often defined by their hypermasculinity. This term encompasses the exaggeration of stereotypical male behavior, which could include physical strength, aggression, and expression of sexuality (Wiersma-Mosley, Jozkowski, \& Martinez, 2016). This trait is often celebrated in college culture and creates space for violence and aggression towards women. While attitudes on rape and towards women vary across ethnic groups, white men still show higher likelihood than any ethnicity to show higher acceptance of rape myths and less empathy for victims (Lee, Pomeroy, Yoo, \& Rheinboldt, 2005; Barnett, Hale, \& Sligar, 2017). Overall, women on college campuses are increasingly vulnerable to rape, and rape myth acceptance is increasingly higher among men than women when it comes to college aged individuals (Lee, Pomeroy, Yoo, \& Rheinboldt, 2005; Barnett, Hale, \& Sligar, 2017). With these statistics and likelihoods, a college campus becomes a place that fosters rape culture or taken-for-granted norms that normalize rape, making the college environment a growing danger for women. 
Rape culture consists of accepted attitudes about gender and sexuality that conceptualizes rape as pervasive and normalized (Marshall University, 2018). It allows for an environment in which rape is present and sexual violence against women is able to be accepted in media and popular culture (Marshall University, 2018). This culture eliminates the will of those who are victim to sexual assault, through the use of victim blaming, explicit jokes, and glamorization of sexual assault (Marshall University, 2018). All of these behaviors are communicated through everyday language used with friends and peer groups. College students are exposed to the behaviors that perpetuate rape culture every day because of the impact language has on its manifestation in environments specific to college campuses.

Similarly, hookup culture on college campuses can easily sway the perceptions of rape, by creating a culture that is difficult to define or understand without proper tools, and rape culture for students on campus creating a strong acceptance of rape myths. Rape myth acceptance is a widely studied topic by scholars, referring to the false beliefs, stereotypes, and negative/positive prejudicial thoughts people hold towards rape survivors and offenders (Barnett, Hale, \& Sligar, 2017; McMahon, 2010; Reling, Barton, Becker, \& Valasik, 2018). Embracing rape myths "muddy the waters" by making it challenging to define what rape is, complicates what a "hookup" means, and includes perceptions that: rape is solely a physical act, victim's response determines rape, and presence of the word "no." Some factors that are less considered among college students when deciding if an experience was rape include: physical harm of victim, emotional mark or scarring of victim, sex of victim and perpetrator (men rape, but victim can be male or female), consent of an unconscious person, and whether rape is accepted as 
wrong (Haugen, Rieck, Salter, \& Phillips, 2017). These simplistic ways of talking about rape offer a clear example that rape is not a heavy topic in college education. If students cannot define the difference between consensual and non-consensual sex, and these are the only ways students talking about rape it perpetuates rape culture.

Many assume colleges should be implementing education programs to lower rape myth acceptance and raise awareness about rape, but researchers are finding many colleges which have implemented these programs do not necessarily have lowered rates of rape myth acceptance among their students (Singh, Orwat, \& Grossman, 2011; Powers, Leili, Hagman, \& Cohn, 2015). And while some studies have found educational programs to lower rape myth acceptance for high school students transitioning to college, they have not been able to track longevity of the attitude shifts (Fey \& Medway, 2006). Why is it that these programs have little to no effect on attitudes towards rape? These authors suggest the attitudes are so heavily ingrained in our culture, everyday language, and societal norms, that one educational course cannot change the altitude of the situation (Fey \& Medway, 2006; Singh, Orwat, \& Grossman, 2011; Powers, Leili, Hagman, \& Cohn, 2015). The way individuals talk and bond over shared experiences leaves a heavier weight on their values and norms than one college class. The language heard from peers, often learned in media, have a higher level of influence than what might be read in a textbook or professed from a teacher. Specifically, the presence of rape myths in media aid in fostering unsafe environments for women. Developing storylines or sharing images that contribute to rape myths including women like to be raped, highlighting violence against women, and associating violence with sexuality, creates space for perpetrators and leaves victims out of the conversation (Phipps, Ringrose, Renold, \& Jackson, 2018). 
College campuses have increasingly high rates for rape. Researchers explain the increased rate as the result of higher risk factors including presence of alcohol or drugs, Greek community presence, athletic team presence, type of college (public v. private), and even the amount of tuition (Wiersma-Mosley, Jozkowski, \& Martinez, 2016). The heightened risks go along with a heightened environment, creating a culture of rape on college campuses. Unfortunately, programming to eliminate rape myth acceptance and negative attitudes towards women has not been successful, and it seems the change has not been successful due to deeply ingrained values within the culture (Fey \& Medway, 2006; Singh, Orwat, \& Grossman, 2011; Powers, Leili, Hagman, \& Cohn, 2015). To identify how rape culture is perpetuated, it is of value to look at social construction of this issue and apply the concepts of language, power, and subjectivity for analysis.

\section{Rape Culture as an Outcome of Language}

The way students engage in everyday talk with friends and peers about dating and relationships contributes to rape culture. With rape being a prevalent issue on college campuses and causing harm and dangerous environments for college aged women, it is important to understand how rape cultures are manifested and perpetuated through language use. As individuals talk, they socially construct particular views of the world, and how the views of the world shape their opinions and images of self, creates particular subjectivities. In this way, language is pollical. From this perspective, language constructs rape culture. As students talk about dating and relationships, they create particular ways of knowing women in relationships that enable particular power relations among men and women, and generate particular subjectivities of women. Identifying how language, power, and subjectivity combine to create particular ways of knowing women 
lead to a deeper understanding of how rape cultures are formed and then held at acceptable standards within college environments can reveal these challenges and maybe how to address them.

What is most compelling about studying language use in this way is that meanings are hidden and taken for granted. Meaning constructed from experience becomes controversial, and powerful, because it involves the personal and emotional investment on behalf of the individual (Deetz, 1992). When meaning is made from our own experiences, it is personal, and when it conflicts with others experiences, it can become controversial. From this meaning making processes, perceptions are formed and rooted in the institutionalized practices surrounding an individual (Deetz, 1992). The way an individual views reality is produced out of a particular subject position defined by the language that socially constructs reality (Deetz, 1992). Often, individuals do not get the choice of what language means to them, and even more, what the language used to describe them means. These meanings and the power relations enacted in them become protected as common sense and accepted as "norm," no matter the impact it may have on a certain population (Deetz, 1992). These norms are then associated with social order, as legitimate knowledge, and the personal identities invested in them suffer (Deetz, 1992). Through this process language is recognized as political because it places individuals in structural arrangements and certain discursive practices that protect and reproduce certain political domination (Deetz, 1992). The way we speak of others, about others, and to others goes further than the surface - it creates and perpetuates systems of power that decide how the language and the person are perceived, before the experience of the individual is able to be voiced and considered. From this perspective, the everyday ways 
of talking with others about dating and sex is more than "just talk." Instead, it creates ways of knowing women, sex, and relationships without their participation in the creation of these ways of knowing.

By gaining insight into the ways college students talk about dating a relationships, the connection to language and rape culture could be better understood. Understanding this connection could allow educators to develop programming and classes that better enables students to deal with and understand the impact their language has on those around them. If the literature on rape culture has found that students are not educated on sexual assault and the impacts is has on the wellbeing of the students on campus (in which case, the impacts are highly negative and harmful), and those interested in communication and power explain the way we communicate and the language we use creates understanding of culture and self, then studying the ways college students talk about sex, dating, and relationships is important and necessary to understand how rape culture is perpetuated. The following questions will guide this study:

$R Q$ 1: How do college students talk about sex and relationships?

$R Q$ 2: How does the language college students use contribute to rape culture? 


\section{CHAPTER THREE: METHOD}

Responding to the research questions posed above requires a method of study that can explore everyday language in use and critically examine it to uncover how this language contributes to rape culture or otherwise reveal the consequences of problematic ways of talking about dating, relationships, and sex. As such, I used qualitative research methods combined with critical analysis to uncover taken-for-granted ways of talking. Inspired by social constructionism, I embrace a qualitative lens for gathering and interpreting data, and, inspired by issues of power, language, and subjectivity, I used a critical lens to analyze the qualitative data. Specifically, in this study, I conducted several focus groups asking college-aged individuals to share their experiences with dating, relationships, and sex. I then engaged in open and axial coding, to arrive at several categories emerging from the focus group transcriptions. Once I had identified categories, I critically analyzed the categories in terms of how they might perpetuate meanings systems that maintain rape culture on college campuses. In this chapter I review my qualitative methodology, explain the methods for data collection and review the process I used to qualitatively and then critically assess the data in response to my research questions.

\section{Qualitative Research and Critical Analysis}

Social construction theory emphasizes the role of humans in actively symbolic resources to objectify, circulate, and interpret the meaningfulness of their environments and their existence (Lindlof \& Taylor, 2011). Meaningfulness is not singular or passively 
absorbed but gained through the engagement of interactions with others and cultural knowledge growth (Berger \& Luckmann, 1966). Over time, these engagements and knowledge become a construction of how society acts and makes sense of reality (Lindlof \& Taylor, 2011). In this way, for a social constructionist, human activity is the key to understanding the power systems and construction of everyday life. Recognizing how communication creates social realities and power relations within those realities, I chose to engage in a qualitative approach to data collection followed by a critical analysis of the data.

Qualitative research aligns with social construction theory in that it makes commitments to examine and explore symbol use, sensemaking, and choice making through human sciences (Lindlof \& Taylor, 2011). These commitments are different from processes of experimentation often associated with the natural sciences. Qualitative researchers, in this sense, argue that realities are unique phenomena (Lindlof \& Taylor, 2011). From this perspective, social realities are created through human interaction and within symbolic practices of expression and interpretation (Lindlof \& Taylor, 2011). Research should seek to achieve deep understanding of human actions, motives, and feelings and illuminate how humans use cultural symbol systems to create shared meanings (Lindlof \& Taylor, 2011). This type of research aims to generate knowledge from credible claims, uses the researcher as the key tool for research, and is guided through verbal and narrative means to collect data (Lindlof \& Taylor, 2011). For purposes of this study, it was important for me to use a data collection guide that would enable me to gain deeper understanding of everyday talk through the narratives of the individuals engaging in this discourse, and use critical analysis to assess how they may 
have come to know this or how these ways of talking were constructed for the individuals who are being objectified by the language use.

Specifically, for this study I used focus groups to capture everyday talk among college students about relationships and dating. After transcribing the data I engaged in qualitative analysis to reveal the meaning embedded in the language and then engaged in critical analysis of emergent categories to assess how this talk might contribute to rape culture. While my goal was to explore the ways college students talk about dating, relationships, and sex, I was also hoping to unpack a deeper understanding about the ways in which students talk to one another, and the implications this has on cultural meanings and practices pertaining to rape culture specifically. Using a qualitative and critical approach to the research questions above, I was able to develop understanding of how rape culture, language, subjectivity, and power are interconnected.

\section{Qualitative Data Collection}

The primary research method for data gathering in this study was focus groups. Focus groups are useful in studying the diversity of opinion on a topic, the collaborative process of meaning construction, and the cultural performance of communication (Lindlof \& Taylor, 2011). In this study, the collaborative process of meaning construction is vital to analyze in order to understand the way everyday talk creates a larger perpetuation of rape culture. The way individuals on college campuses talk about sex and relationships with their friends and peers, will reveal the way they make sense of rape culture as it is, and how language contributes to it.

To recruit participants for the research study, I went into undergraduate classes and resident hall meetings to ask individuals to participate. The verbal invitation script 
included the topics to be discussed (dating, relationships, and sex in college) as well as the type of individuals needed (Boise State University students over the age of 18), the expectations of time commitment (two focus group sessions lasting approximately one to one-and-half hours), and the perspective time frame the focus groups will take place. Potential recruits were given a flyer with information and asked to fill out a sign-up sheet with their name and contact information if they were interested. The flyer included all the information from the verbal script, my contact phone number and email, a statement regarding what department is conducting the research and who the conducted research is being completed under, as well as the IRB approval number. Individuals who were interested and provided contact information on the sign-up sheets were then contacted using a drafted, standard email which listed out what was being asked of them, the times, the dates, and locations of focus groups. The focus groups were held in private meeting spaces in the Student Union Building, in the evenings to avoid conflict with work schedules and night classes that students may have obligations to.

I chose focus groups as my method of study because I am interested in the language used and how meanings are negotiated among individuals about dating, relationships, and sex and focus groups allow for meaning making to take place among many individuals. I conducted four focus group sessions with an average of five individuals in each focus group; ranging from two participants to eight participants in each group. However, gaining participation proved to be difficult for such numbers, and I had to conduct some odd-sized groups in order to gain the holistic view of an accurate representation of data. 
Because I am interested in the ways men and women use language and negotiate meanings differently, I decided to conduct focus groups based on gender. This proved to be a difficult area to address, when it came to recruiting students and asking them to separate into the binary, I quickly realized certain voices not conforming to a gender binary were eliminated in my method chosen for research. The objective of splitting up groups by gender was to understand the way peers of different genders may engage in discussion about dating, relationships, and sex when they are with alike peers and opposite sex peers. While I was able to do this and had to more narrowly define my study as the evaluation of dominant discourse, it was certainly disheartening to see where voices are lost in research. I was able to offer individual interviews to students who wished to participate but did not identify within the binary, and while they declined the interview, it was an important experience to note for any researcher who should continue work evaluating dominant discourses when we consider what that means for the minority populations who are, too, affected by the dominant discourse at hand.

It is also important to note that by separating gender and operating in an assumption that gender is binary, this study naturally perpetuated heteronormativity, specifically when looking at how it perpetuates views on gender and sexuality. As I delved deeper into my research, it became apparent that my participants and my findings, while not all identified as heterosexual, were all operating out of normative views of dating as enforced by heteronormative values, assumptions, and beliefs. In dividing women and men in search of dominant language, I recognize the issues with gender being presented as binary and the implicit heteronormativity that this study perpetuates. Sexuality and gender are not binary, and this study operates as so. 
Ultimately, I ended up leading one focus group consisting of eight women participants. A fellow graduate student, who identifies as a man, led one focus group consisting of men, in which only two participants attended. Together, my co-facilitator and I led a combined focus group comprised of both nine men and women. At that point in my research, I felt I needed more participation from men, so I conducted a second focus group with just men, in which five participants attended.

The focus groups were a valuable method for investigating everyday language about sex, dating and relationships because the process exploited the group effect, taking advantage of the fact that, in both guided and ordinary conversations, individuals tend to draw upon shared experiences (Lindlof \& Taylor, 2011). The chaining of conversation within the groups brought to the surface ideas, expressions, and experiences that may not have come forward in a one-on-one interview. The goal was that group members would create complementary interactions, which allowed them to come to a consensus on, for example, the ways in which they talk about sex with friends, and then through conversations about this consensus, revealed their own observations and subtle understandings of the meanings, like their attitudes towards women or feelings towards dating (Lindlof \& Taylor, 2011).

Upon arrival to the focus group sessions, participants were briefed about expectations of length of the focus group, topics to be discussed (dating, relationships, and sex in college), and common ground rules (respect of one another and participant protection when sharing within the group). They then were read the informed consent aloud by myself, and asked to sign the consent form, which included information such as: they did not receive any benefits other than opportunity of participation, their names and 
identities will not be disclosed through any analysis or written work, and if any feelings of uneasiness arise resources on campus are available. I then asked them what questions they had, and after any questions have been answered, the focus groups began. I quickly reviewed, once again, the "ground rules" for the discussion which consisted of being sure to let people finish their ideas and then respond as well as feeling open to share all ideas, and to respect the ideas of others (to talk about ideas and not attack other participants). The focus group then consisted of asking questions about college student's experiences with dating. First, they were asked what instigated dating looks and feels like. Then, they were asked questions specific to relationships. Specifically, they were asked about shortterm relationships, long term relationships, and outsider attitudes towards relationships in general. Finally, the participants were asked questions about sex and how it pertains to their experiences with dating and relationships. The overall goal is that talking about dating, relationships, and sex would reveal common ways of talking and subsequent meanings maintaining specific power relations and subjectivities enabling rape culture.

The focus groups provided opportunity to capture the discussion that emerged from in a series of questions that were formed and approved through the IRB process. The focus groups were audio recorded to aid in the transcription of the data for this research. In the following section I review the process for my qualitative analysis and discovery of emergent categories, and I follow with emerging themes. From there, I engaged in a critical analysis, connecting the categories that emerged to the problematic ways of everyday talk that perpetuates rape culture. Through this process, I was able to analyze data in ways that answered my initial research questions. 


\section{Qualitative Analysis}

Using a qualitative approach to analysis, the transcriptions, serving as the data source, were coded, then open coded, and categories that emerged were identified through the qualitative process (Lindlof \& Taylor, 2011). During this data immersion phase, I engaged in conversations with my advisor and peers about the data and what it meant (Tracy, 2013). I listened to the audio recordings several times, and read the transcriptions, over and over again. While doing this, I wrote notes, created diagrams, and asked questions like, "what is happening here?" and "what is the story here?" From there, I was able to gain insight and understanding of the narratives my participants shared simply by listening, reading, and engaging in constructive conversations about the data.

Next, I engaged in primary-cycle coding, and identified first-level codes (Tracy, 2013). Primary-cycle coding happened, for me, simultaneously during my data immersion phase. This is where I read and re-read while looking for the first-level codes that would focus on what was present within the data (Tracy, 2013). As part of this process, I looked at what the laughter, the silence, and the choice of words might have meant in relation to the questions asked throughout the focus groups and how participants responses were in reaction or relation to another's response to a question. I then began to focus on the second-level codes and engagement in a constant comparative method of data analysis. I used the first-level codes as signifiers that something may be present within that section of the data, and the process of data emersion sparked questions about the data. However, the second-level codes helped in developing categories and analyzing meaning behind the categories (Tracy, 2013). In order to bring together different firstlevel codes to an overall category or second-level code, I engaged in a constant 
comparative method of modification of each code, looking at how different ones could interconnect and what meaning the first level codes gave when connected to one another (Tracy, 2013). From here, I developed a code book of categories, codes and descriptions, and key quotes that would later be used in the findings section of this paper. Code books, while not necessary, are a form of data organization and a display that offers a visual representation of the data and the definitions you as the author have linked to the codes and categories (Tracy, 2013). Throughout the data immersion process, the coding and secondary coding, and the creation of the code book, I also utilized both analytic memos and analytic asides (Tracy, 2013). These are notes that provide context for the researcher throughout the data analysis that offer their own site of conversations and "brain dumps," (Tracy, 2013). For me, these became incredibly helpful when I jumped from the qualitative data analysis to the critical analysis, so I could begin to piece together my interpretations through a more critical lens as a researcher. Finally, I created diagrams that explained the dating process, and guided me through my qualitative analysis to better understand the ways in which women and men talked about dating, relationships, and sex in different (or similar) ways. These diagrams, while not a part of my findings served as a visual representation to aid in the understanding of answering the research questions presented in this study.

Embracing this notion and this explanation of theory in research pointed to how these human interactions that emerged from my focus groups and transcriptions were truly and inherently meaningful (Lindlof \& Taylor, 2011). By using this form of data collection and analysis, I was able to answer questions about language, subjectivity, rape culture, and power can be analyzed and answered on a deep, meaningful level that looks 
at how interactions between humans create this culture encompassing those key aspects of the study.

\section{Critical Analysis}

However, while my goal is to develop understanding of the language used, I am also interested in the politics of this language and the impact the use of language has on the manifestation of rape culture and on the individual. Embracing this critical perspective to language and meaning, I also engaged in critical analysis of the emergent categories arising from my qualitative analysis. The critical paradigm promotes the ethical and political study of the relationships between power, knowledge, and discourse. These relationships are produced by situations of historical and cultural struggle (Lindlof \& Taylor, 2011). Critical theorists aim to understand power relations in order to develop a sense of how certain phenomena have been socially and historically constructed (Lindlof \& Taylor, 2011). It claims that these power relations are developed through discourse, creating subject positions that make the self, other, and World a key component into developing an individual's worldview (Lindlof \& Taylor, 2011). Critical theory also commits to the connection between research, facts, and values. Research cannot be divided from its values (Lindlof \& Taylor, 2011). Embracing these critical perspectives, I engaged in critical analysis in hope of revealing how cultural meanings and practices associated with sexual violence are shaped, how oppression of women is created and reproduced.

To engage in critical analysis, I critiqued the emergent categories to reveal how the language used throughout the focus groups is problematic. To do this, I combined data from all focus groups to critically analyze by gathering a combination of asides, 
commentaries, and coding narratives (Tracy, 2013). While analyzing this data and uncovering emergent categories, I examined the patterns of words used in the focus groups, the specific word choices, and the description of where or when the conversations actually occurred to gain a contextual understanding of why those specific words and patterns have emerged now. Specifically, I examined how all the women and men's groups interacted versus how the combined group interacted. I looked at the patterns and rhythms that emerged, what vocal tones were used, where the storyline comes from, as well as what life scripts are being invoked (Lindlof \& Taylor, 2011). In order to critique the language, I pulled specific terms and phrases that connected or resonated with the group in certain ways. For instance, an individual from one of the focus groups referenced a woman as a slut because she simply did not want to date her. This created a cascading effect in which the men shared names and phrases they used to describe women who may have hurt them or complicated their subjectivity of power when it came to dating relationships and sex. The names and phrases were signifiers to me that this would allude to significant findings, as well as the way the men felt open to share and bounced the ideas of these experiences off of one another. Identifying and analyzing these key components enabled me to understand what the categories mean, and how the language used contributed to rape culture, or meanings that constitute the subjectification of women, and allow me to respond to the second research questions.

Overall, in order to respond to the research questions above, concerning language, subjectivity, rape culture, and power, I used a combined interpretive and critical method of study that can aid in gaining a deeper understanding of language use and critically examine it to uncover how language contribute to rape culture and the problematic ways 
of talking about dating and relationships. This study thus focused on interpretive research methods with critical analysis to reveal how the taken-for-granted ways of talking contribute to rape culture on one college campus. 


\section{CHAPTER FOUR: FINDINGS}

The findings of this study are presented in two sections. The first section provides the outcomes of the qualitative analysis revealing how women and men talk about relationships, dating and sex. The section is organized in terms of how the dating process is talked about by women and by men. After reviewing the ways participants talked about relationships, dating, and sex, I respond to my first research questions with an emphasis on the different language used by women and men. The second section provides the results of my critical analysis of the ways women and men talk about dating, relationships, and sex. In this section, I critique the realities and subjectivities formed through the discourse emerging from the focus groups, and respond to my second research question asking how everyday talk about sex, dating, and relationships perpetuates rape culture on college campuses.

\section{The Ways College Students Talk about Dating, Relationships, and Sex}

\section{The Language Used by Women: Describing the Dating Process}

The most interesting finding that emerged when qualitatively assessing the focus group transcripts is the ways women and men described the process of dating, relationships, and sex. Both describe it as a linear process that includes meeting someone, determining what is next for the relationship, and how the relationship concludes, however the ways of talking about each component of the process and the language used is quite different among the women and men in this study. 


\section{Meeting Someone}

The process of dating as described by women begins with meeting someone. This initial meeting could happen in a variety of ways including bars, a parties, or on a dating application like Tinder or Bumble, a class, at work, or through mutual friends. However, the location and proximity of individuals the women were pursuing was a significant determinant of how they may meet someone. It was more likely that the participants would pursue someone who lived close by or that they went to school with, than pursuing someone who did not live close or spend time in similar locations that they did. Vanessa, for instance, emphasized how important proximity has always been in her relationships, "whether that is working with them, being in the same social circle, and then you just started hanging out more and talking." The women also explained that the way you meet someone and your intentions when meeting someone are strongly linked. Serena shared that she, "think[s] it just depends on what you are looking for. I know a handful of people who are 'dating' and they just jump on a dating app and start swiping right." When meeting through dating applications like Tinder and Bumble, the women shared that the type of advances they receive are crass or unwarranted. Kathryn shared, "it is just always so raunchy. Guys will say things like, 'sit on my face,' or whatever, and that is their pickup line." Most women agreed and shared that people can be looking for different things when it comes to dating, however, regardless of their intentions, nearly all initial situations in which they met individuals of interest involved alcohol. Casey shared, "I always go get drinks. Always. Happy Hour, an outdoor bar, whatever it is we just always get drinks." Charlie also emphasized the relevance alcohol played in the dating scene for college students by sharing, "I think dating in college is almost always originated in some 
form of drinking. So, for people that are 21 and older, that could be at a bar and for people that are under 21 that could be at parties. Even if you met them somewhere else but you are texting them, you almost always invite them out to a party or bar, or they invite you out to a party or bar to meet up with them and their friends."

After the initial meeting, women described how conversations are initiated and an exchange of phone numbers or Snapchat usernames typically occurs. At this point, two stages emerged if the woman was interested in pursuing any further relationship with the man. These stages were described as hooking up and talking or "dating," in which the quotations were intentional to separate from dating or relationships. At both stages, women admitted to perceiving more stability and reciprocation than men were often actually offering. Serena offered insight to her own experiences, sharing that she thinks,

we are all guilty of it but saying like, 'Oh we hung out five times but it's in a group, we talk everyday but it's in group chats, he always snapchats me but they are mass snapchats that were sent to his friends too; so he must really like me,' and that's just what we form in our heads and it comes from what we want or are looking for, rather than what it actually is.

The first possibility emerging from the focus groups was discussed as the "hookup." Hookups were almost always associated with the use of alcohol, as discussed above, and was considered a form of casual sex. The focus group came to a consensus that hooking up, among them, meant having sex (intercourse) and anything less would not be hooking up. Serena's comment best reflected this shared sentiment, "I have a roommate who was in a four-year long relationship, whose boyfriend flew into town. They had never had sex, and when she came to us and said, 'Oh we hooked up,' we were like first of all - you don't hook up with your boyfriend. Second of all, what happened? And she told us they made out on the couch! That is not hooking up, that is making out 
with your boyfriend of four years who literally flew here to see you." She explained that if you were already in a relationship with someone, that would not be hooking up and that hooking up had to be more than kissing, and almost always alluded to having intercourse with the other person.

When the focus group talked about how and when individuals decided to hook up, they all agreed that you do not really know for certain until it is happening. Hookups might occur quickly after initially meeting and talking with someone or after spending some time together. However, the discussion revealed that one can typically expect regarding when physical intimacy might happen after initially meeting someone. For instance, Jessica explained,

I have a roommate and she recently has been in the dating scene and I think every time she goes out to drinks and dinner, she expects to have sex with them, or she is expecting him to expect thing. Like she goes into the situation knowing that the man is expecting to have sex with her or take her home. But also, she expects it. She cleans her room before she goes out every time, and it seems like it is something she is communicating in their plans. In this situation, she is just hooking up with them and maybe talking to some but not dating anyone.

Whether the physical intimacy is expected or unknown, Blaire shared that knowing someone prior to initiating any kind of talking or hooking up could give you insight as to what to expect. She explained, "you know their expectations usually because you might have heard about them or run in the same social circle and know what they would typically be known for doing (dating, hooking-up, etc.). And you know if they text you at 10:00pm, they don't want to go on a date or hangout, they probably want to have sex or hook-up. But if they text you at 8 am or noon, they probably want to actually talk to you." 
The women in the focus groups offered many unsaid rules they adhered to when they were in the "hookup" part of the dating process. For instance, women would never text first and would always wait to see how the man felt and what his intentions are. One participant shared that she, "would have rather died than text her fiancé first," when they began talking but another participant did say that she likes to be direct and asks what the expectations are. Everyone else in the focus group shared that they would never do that. They said they know the man's intentions based on the time of day he would text them and how often he would text them, and this is usually the biggest way they can indicate what is going on between them and the other person. Serena shared that you know this because, 'there is just a difference. Like when you ask,'You up?' that means they want to hook up and see if you are awake and able to. If they text you that at noon though, it's like are you sleeping or napping or are you awake? So the time of day matters." The group agreed that this was a huge indicator of what was expected even from a simple text.

The second possibility after initially meeting and talking with someone is talking or "dating." Described as talking or "dating" with which air quotes around it, was distinctly different than the traditional use of the word dating and not the same as a relationship. As Jenny explained, "If people are texting a guy and meeting up with him at parties they will be like, 'Oh we are talking, we are 'dating,' and I think that is when the air quotes dating comes in.” In this stage, people would be Snapchatting, texting, and likely only seeing each other on the weekends at parties, at bars, etc. At this point, they are likely getting to know the each other but the stage is talked about in terms that are ambiguous and casual. You often do not know the intentions of the other party and are 
left to decipher or figure out what direction the relationship has the potential to develop. Lily shared from experience with her current boyfriend, noting that, "It takes time (to read them and know what they want). It took me three years and it just progresses until you know." Blaire added that there was an emphasis of not knowing between them and the man, noting, "I think to them, it's sometimes even just messing around when we are evaluating it and trying to read them but they don't have any idea."

In one focus group, a significant emphasis was placed on double texting and what that looked like in different stages as well. Double texting was described as sending multiple text messages in a row without a response in between them. Doing this when you are dating or in a relationship was okay, but never when you are just "dating," talking, or hooking up. This is an example of one of many of the societal norms that the focus group could not identify why it happens or how they know not to do it, but agreed that everyone 'kind of just knew.' Altogether, there were a lot of societal norms the women needed to follow at this stage, and a lot of guessing to see what is next. During this time women describe that there was a lot of communicating via text message or Snapchat, and they are seeing each other, and likely being intimate, there was little communication at this stage that actually describes or explains where the relationship is. For example, Blaire emphasized that, "you never know what they are thinking. Even after three years in a relationship, it feels like I am just beginning to understand what my boyfriend is thinking but that took a lot of time and a lot of work." For women, these stages of the dating process were complex and ambiguous, which could often lead to misunderstanding or hurt feelings. As mentioned above, in these stages, women 
perceived themselves to be more invested than the men, and had difficulty understanding what the men wanted and what might happen next.

\section{Determining What is Next}

At this point, the women discussed how a relationship could take two routes. You could either begin dating (without the air quotes) or begin a relationship. In this phase dating is described as more serious than hooking-up or "dating," but more ambiguous than being in a relationship. The women discussed that during this phase of the process when you are dating someone, you are going to dinner, going to movies, and getting to know the other person. This stage could be defined by both parties as either official or not official and would likely mean that you are interested in pursuing a relationship.

However, there is a possibility to go from "dating" to a relationship but you could not skip dating or "dating" and go straight from hooking up to a relationship. In both instances, there is usually a conversation that happens between both parties, sharing what they want out of the relationship. Serena shared that,

if people are talking or "dating", then they are seeing each other on Friday and Saturday night at a party and likely hooking up. This is like having sleepovers, going to parties and drinking, and Snapchatting. If they are dating or in a relationship, then that is when you are committed to a person. The feelings are mutual. It's spending one on one time. It's wanted by both parties.

In this stage, the individual is often trying to get to know your friends and your roommates as well, and often shows investment into your life as it is. This was often described as the hope for a relationship or as the fantasy stage. Women said they would love to be going out to dinner and movies and to be asked out on dates, but that is just not how things are done. Blaire emphasized this and noted, "I guess that could be another 
definition of it, is that dating is kind of like the fantasy stage. And then once you are in a relationship you know it's for real. You're in it together, you know?"

\section{Relationship Conclusion}

The final phase of the relationship process involved how it was hoped to conclude. The women had little to no discussion of what the dissolution of a relationship looked like or feels like. However, the women did not discuss what rejection in pursuing a relationship looked like, but discussed what might happen if a date did not work out and what they were looking for when it came to dating, relationships, and sex. At one point, an individual did share what happens when you go on date with someone who you may not want to pursue a relationship with, Serena noted,

I started talking to this one guy that we had mutual friends, and we went on a date to coffee at like noon one day and it was great and we talked and we had coffee but I wasn't really interested. So it wasn't horrible but it was just like yeah you're nice, we have mutual friends, we will see each other around.

For women, the end of the relationship did not mean that someone was wronged or something even went wrong, it usually meant they were able to find out about the person, get to know a person, and then still be friends with them possibly.

There was, however, much discussion and emphasis on the purpose or goal of dating. The women seemed to agree that finding a life partner, friend, and husband was the ideal goal of dating, and that if the relationship ended in marriage, you must have done everything the right way. Finding someone whose values aligned with yours and that you enjoyed spending time with would be an ideal situation. Blaire shared,

I mean the best part of dating is you could find the person you end up wanting to spend your whole life with, which is pretty amazing. I think that is the biggest benefit of dating. You get to experience what different people are like and figure out what you like, what you don't like and then find someone who has everything that you are looking for. Hopefully, I mean that's what we want it to be. 
Vanessa also added, "that is the benefit, is surrounding yourself with people whose values align to yours and finding out what is important and what is not important." To women, the point of the relationship was to find what you want in a partner, and to eventually find a partner that would last long term.

The Language Used by Men: Describing the Dating Process

For men, the process of dating, relationships, and sex were described in terms of the same three key processes of meeting someone, determining what is next, and concluding the relationship. However, the process was described in a much more complicated way, and could take a variety of routes that were dependent on a mixture of variables.

\section{Meeting Someone}

The men in this study explained that dating, relationships, and sex begin by meeting a woman. Similar to the women in this study, the men explained that meeting someone can happen at a bar, a party, on a dating application like Tinder or Bumble, a class, at work, or through mutual friends. And again, when meeting someone, alcohol was almost always involved, whether that be at the initial point of meeting or throughout instigating further communication or interaction. When Nate described what meeting women and pursuing women in college was like, he said:

Chaffee parties, lacrosse parties, seemed to spread like wildfire. Anytime there was anyone at the house, it seemed like it would turn into 200 people there. So if there are 200 people there is definitely going to be a lot of girls there. Also, Tinder, definitely. I think just like he was saying, you need to take a small step forward, you get their number, and you get their snapchat and you start talking to them. I think that initial stage where you guys just meet and are in constant communication is how most of my romantic relationships form...I guess I call them hook-ups or talking, but most of the time it would be talking to a girl and then we would end up having sex or I was pursuing her to have sex with her. If I liked her enough and we clicked personality wise, then we would be dating. Like 
my girlfriend now, I pursued her because I wanted to have sex with her but now I actually really like her.

\section{Determining What is Next}

After meeting a woman, the process was described more as a series of questions men ask themselves rather than a series of steps. Initially, the men discussed the pursuit of sex as the main goal after meeting someone with whom they are attracted. For instance, Chuck said, "I mean I think we all know what we want when we meet them, it is just a matter of how we want to approach it and how we plan to go about getting it." Once they have decided they wanted to have sex with the woman, they would later consider if they wanted to pursue dating them. The discussion revealed three possible routes that could be taken, depending if they want to date someone, do not want to date someone, or are uncertain.

If the men determined they wanted to date a woman, they explained they would not try to have sex with that person, yet. They described that having sex this early in the pursuit of a woman would complicate things and make it difficult to form meaningful conversations and connections later on. Chuck shared that in pursuing his current girlfriend, he described that he did not want to have sex with her, initially, "because it would make forming a real connection hard. Once you have sex with someone, you have this moment of like, 'we just saw each other naked,' and it makes talking or getting to know each other really awkward." Once they made this decision, they would ask for their number, and initiate interest by being casual but not showing too much interest, to be sure to adhere to social dating cues and norms they felt college culture implied when it came to dating, relationships, or sex. If they rushed things, they worried she would think they liked her too much or that they were clingy. Lyle shared, "you wouldn’t want them to 
think you were clingy. I mean if you text them more than once, or text them at the wrong time, it could give them the wrong idea. You just don't do that stuff." They would continue pursuing interaction with them by inviting them to parties, inviting them to their houses, and eventually, asking them out on a date. At this point, the men talked about being in the stage of talking, that might progress into dating. The men discussed this in terms of not yet having committed to the person, and thus they could still be seeing other people. Nate reflected on a time when he was at this stage with a woman who wanted to create clarity in the relationship before leaving on a vacation. He reflected,

Well I actually still am trying to figure out what happened. I asked her what she wanted out of it because if it was just casual, I was going to hook-up with some girls I knew at home. I did like her, and would have liked to just be seeing her at that point but wasn't sure how she felt. After I asked that, she got so mad and never talked to me again.

After he reflected on this, the group engaged in some conversation about what that means, what they would have done, and Nate defended what that meant to him when one member of the group said that seemed demeaning to the woman. Nate said, "Yeah, but I said it because I cared not because I wanted to go hook up with the other girls. IF I didn't care, I would have just hooked up with them and not told her." If the men did choose to continue into a relationship with the woman, and once they begin going on dates, and want to make their intention clear, they will ask them to be official. This looks like a formal date, where they ask them to be their girlfriend, to be "theirs," or to be exclusive.

If, however, men decided that they did not want to date or pursue a long-term relationship, they discussed that their main focus was on initiating sex and hooking-up. 
The men discussed that hooking up meant they were having sex. And with hooking up,

came certain societal norms they would need to adhere to or understand. Nate said,

Well [to hook-up] you meet someone and it depends on the person and sense of maturity because I think hooking-up in high school to college goes from kissing to always having sex. And if someone tells you they have hooked up with someone, you can assume what they did with the person based on what is expected. Like my girlfriend's roommate has never had sex so when she says she hooked up with someone, I always assume they have just kissed. But I do not consider kissing as hooking up.

Everyone in the group agreed that if you said hooking up, it meant you had sex with that person. Dan noted, "I mean I have never heard of hook-up as anything else." However, they did emphasize that if someone said hooking up and was dating someone, they would not consider that hooking up. In a greater reflection of hook-up culture, Bart offered that:

I think hookup culture has done something pretty strange with hookups because like on one hand you have how comfortable people are with sex, which has gone up and that good because people should be open to having sex, but at the same time, the emotional capacity for understanding and talking about it has ironically gone down. It makes me think like what would happen if for some reason you were forced to talk to them for an hour after sex. It would be really awkward at first because that is not what we are used to but you would get used to it and you learn how to deal with it because people are very open to physical action now but once it comes to the emotional capacity, you could learn to talk with people about it and understand that even though you just had sex with a meat sock, you have to deal with that person and they are actually a living being that has emotions and deep complexity. But then again, girls always say they are looking to have deep conversations but it's like oh fucking come on, we will have sex and then you have no idea what to talk about.

If they decided the woman was cool or they like them as a person after hooking up, they might initiate hanging out outside of sex, or hookups to see where things might go. Deciding if a man likes a woman was described as being dependent on how easy it is to talk to the woman and what common interests they may have. If they like them, they would continue pursuing interaction with them by inviting them to parties, inviting them 
to their houses, and eventually, asking them out on a date. Chuck reflected on how he pursued his girlfriend, sharing that he,

devised a plan. I found out we worked together and began asking her to come to parties but she always said no. So I found out a kid in my class was her roommates boyfriend and I was like 'oh fucking perfect.' So I invited him to the house party, telling him to bring his girlfriend and her roommate. Then I asked her to come at work and let her know I invited the kid from class and his girlfriend - I told her they had said yes. And it worked, she came to my party that weekend and now we have been dating for three years.

At this point, they are likely in a stage of talking, and may progress into dating.

They have not yet committed to the person and could still be seeing other people. Once they begin going on dates, and want to make their intention clear, they will ask them to be official. This looks like a formal date, where they ask them to be their girlfriend, to be "theirs," or to be exclusive. If they decide they do not like the other person, they can decide to continue hooking up with them, be friends with them, or cut off communication with them. Usually, this is where they would ghost someone, in order to avoid conflict or confrontation. Nate reflected on this as a negative part of dating,

because while hook-up culture is nice, you get the stuff like ghosting where you don't want to tell someone you don't like them, because you know you don't want to be, I mean if you are a super nice person you don't want to make people feel bad. So, you have this problem where people just stop talking to you or you stop talking to them, where this is this sort of lack of willingness to communicate. I feel like that would be one way that dating could be better, is people being more willing to communicate.

When he was asked what ways they could communicate better, he noted, "about their feelings, which is the hard part of the whole thing is people having difficulty talking about their feelings." Chuck added, "and what they want." If they were not sure if they wanted to date them initially or were not looking for a relationship, they would hook up with them and then see what happens. This would bring them to follow one of the first 
two routes from above, or altogether stop talking to them which was usually not communicated and did not offer much closure.

\section{Relationship Conclusion}

Relationships for men can end a variety of ways, and they often see it as you either date and break up or you date and get married. However, for all the other types of relationships you have (dating, hooking-up, or talking), those could end in a variety of different ways, most ending because people do not know what they want which the men attributed to women specifically not knowing what they want. Chuck shared,

No one really know what they want. I think about anything. We just do it right now because it feels good. But if you would really think about what you want longer as it becomes a really challenging conversation because you either have to face things that you didn't want to face for yourself and like what you're planning on doing. But there is the expectation that we are in college and this is a four-year university. If you're dating someone in college, like who the hell knows what's going to happen at the end of that? You're going to stay together and you're going to get engaged. Do they want to move to a different city? Did they move from a different city and their parents live somewhere else? Like you have all these things that suddenly become super hard life choices that your forced to make by a deadline.

However, what was most prevalent among the men when it came to discussing rejection or the resolution of the relationship, was to blame women. This not only was because they felt they never knew what they wanted, but admittedly, because they wanted someone to blame who was not themselves. For instance, Bart referred to his exgirlfriend as, "Lacey the cunt," because his life was difficult after their breakup and later admitted that he may have taken the breakup hard, and that is why he used hurtful words to describe her. Chuck shared that not only did this happen frequently among his friend groups as well, but that even talking about women become derogatory when it was just within a group of men. He shared, 
Men talk about relationships differently than women, and talk about them differently when a woman is in the room. A lot of my friendships in college formed from late nights, drinking, and talking about girls but as soon as a girl was there it changed the whole conversation. And that's also when the hard rejections come out, like instead of saying she didn't like you because you are ugly, it's like, "oh she's such a bitch,' or, 'she's such a slut since she just wants to sleep with other guys. We do this rather than accepting that maybe something is wrong with me, like maybe I am overweight or I am just a dick.

The group agreed this is usually something they all do not want to come to terms with and blaming someone else or finding fault in someone else becomes easier. They also noted that women tend to go into more detail about experiences, whereas men explain that they "fucked," and tend to move on. However, Chuck reflected on a time he found himself in a male space and felt validated by his friends through these type of conversations,

I felt safer but also knew I was being judged in a different way. So I lied about a good portion of what actually happened when they asked about things. I remember one time I had sex with a girl and my friend who was sleeping outside the room heard, and the next morning he like praised me for all the screaming and moaning she did. I knew that was just what she does, or maybe she was overcompensating or trying to make herself look hot, but I knew I didn't do that. Or maybe I did. But in the end it felt good to have him come to me and be jealous of what I as a man could do to make her feel that way, even though it wasn't true.

In this situation, the group reflected on a number of moments where they masked the truth to make themselves look and feel better in front of friends, and admitting that many times this was at the expense of the woman.

Dan noted that he has observed this type of behavior in college, and that he felt male dominated spaces made more room for men to find excuses for their own behaviors. He shared a story about a fraternity brother opening meetings by calling an advisor on campus a bitch, explaining that she was the reason why things were not completed. He shared, 
I knew her, and I worked with her, and I knew that wasn't happening but he used that as an excuse to cover him not getting things done. I reported him and after that, it's like people in my fraternity don't talk to me about that stuff because they knew it makes me uncomfortable, or maybe I make them uncomfortable when I am calling them out.

To Dan, this was a moment of speaking out and to the other men, it was another reason not to say anything in defense because a woman (myself) was in the room. They all shared that even my presence as the researcher in the room, the entire dialogue and discourse was monitored and shared differently than had it been only men in the room. Overall, the dissolution of a relationship seemed to mean a great emphasis on rejection, whether that be in an actual relationship or just dating or talking. They did not note much on the way a hook-up might end, but the overall consensus was that the end of a relationship often meant blaming the woman for the end whether it was her fault or not. $\underline{\text { How College Students Talk about Dating, Relationships and Sex }}$

The goal of outlining the way women and men talked about the process of dating was to better answer and understand the first research question asking how college students talk about sex and relationships. The way women spoke about these topics and the way men spoke about these topics within the focus groups gave me insight into how they might also use the same kind of language and discourse in everyday conversations they have with friends and peers.

For women, this meant talking about dating, relationships, and sex in relatively uncomplicated ways. Their idealized forms of relationships with men were talked about in straightforward ways and they wished for common goals and communication to be at the center of the relationships. While this may have been what they wish for or idealized, they did express that there was often confusion with defining the relationship or even 
specific terms that relate to dating and relationships. When I drew out a diagram to better follow the way women talked about dating, it looked like this:

Process of Dating - Women
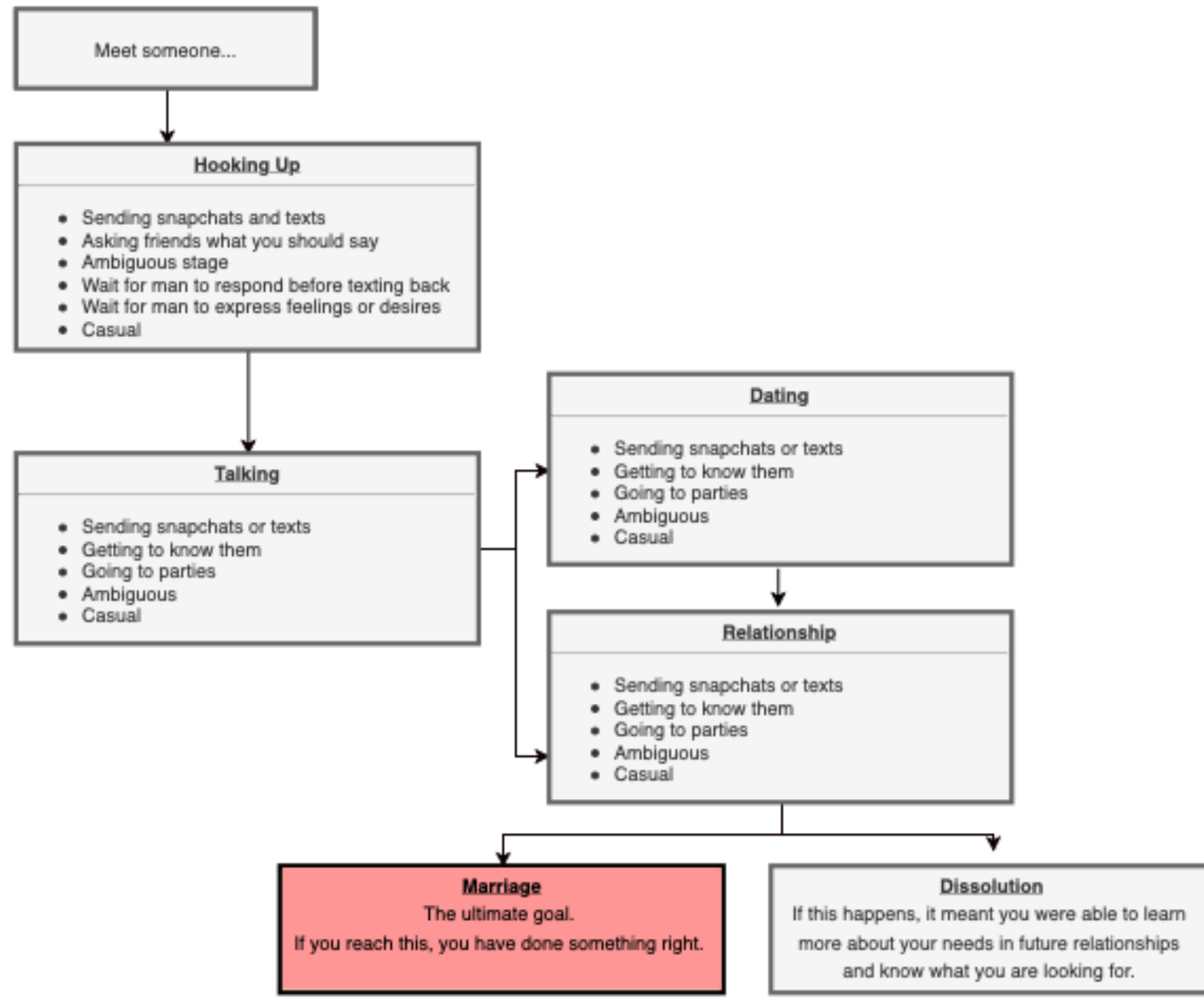

Relationship

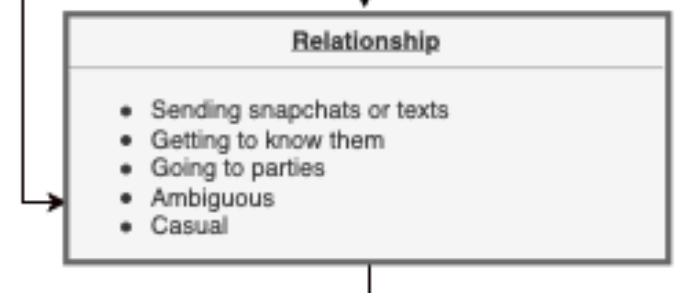

Figure 1. Process of dating as described by women. This diagram emerged as a result from the transcriptions of the focus groups. 
Specifically, when women described the dating process with terms like ambiguous, casual, and unknown, I was able to conclude that the process was confusing for them. They dove even deeper to use verbiage like waiting or anticipating to describe waiting for a reply to a text message, anticipating that sex would be initiated, or even just waiting to understand where the relationship was. These are some of the specific examples of language that women used to describe the process of dating, sex and relationships that brought me to my findings.

For men, however, the talk about dating, relationships, and sex was expressed in more roundabout and complicated ways. This reminded me of a Cosmopolitan Magazine Quiz, maybe titled, "Should I date her or not?" They used simple questions that guided them from one stage of the relationship to another and claimed that women were the source of any ambiguity or confusion when it came to relationships. The most interesting finding that emerged from the focus groups, was the men's ability to justify their behaviors, like lack of communication or unwillingness to commit. They admitted that they often find ways to blame women, and that they would rather blame her because it is easier, than looking inward at what issues they may have brought to the relationship. 
When I drew out a diagram to better follow the way men talked about dating, it looked like this:

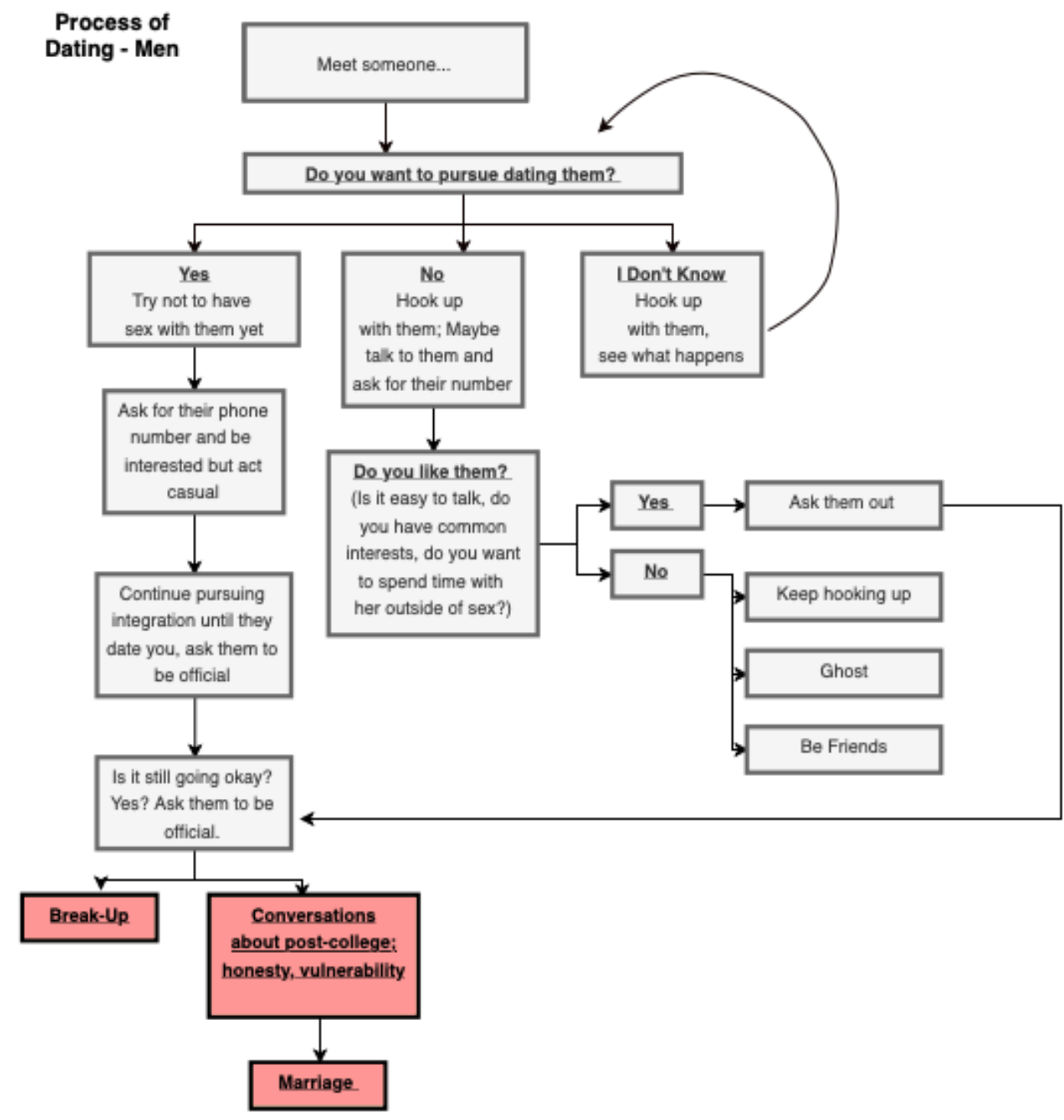

Figure 2. Process of dating as described by men. This diagram emerged as a result from the transcriptions of the focus groups. 
Specifically, when men used terms like, 'you have to ask yourself,' or, 'when you make the decision to date them,' it was clear to me the agency they felt just based on their language choice in describing the dating process. They used specific terms like cunt, meat sock, slut, and bitch to describe women who had hurt them or challenged their ability to make those decisions in the process of dating, sex, and relationships. Looking at the specific way their language was used, and when it was used, enabled me to come to the findings and conclusions that I did as I interpreted how language was harmful in these experiences they shared, and in what ways it was harmful in relation to rape culture.

These diagrams offered insights into how dating, relationships, and sex were verbalized into a process that was not easy to understand for those on the other side of the relationship. The terms they used and the justification of the process they offered created realities and subjectivities for men and women that I analyzed and discuss in the next section of this paper. It put some individuals in certain positions over or under others, and created power dynamics that both sides may not have seemed to recognize (other than one male, who might be considered an outlier, or exception). Even when we brought up ideas that the other men did not seem fond of, I watched him back down and let the others make excuses. Overall, the focus groups revealed that the way women and men talk about dating, relationships, and sex differ. Women talk about dating as an experience they can learn and grow from, involving feelings, emotions, and understanding. Men talk about dating as an experience that should get you from point A to point B and the journey in the middle is complex and complicated because no one knows what they want (or so they perceive). While the actual stages of dating and the terms used for dating were similar, the way they got from one point to another was entirely different. The women 
talked about it as a series of directions. Once you completed one direction, you would move onto the next. The men took a path that acted as series of questions, and their answer to each question determined what happened next. The biggest commonality among the findings was the marginalization of women in both groups. Women expressed they had little to no power to change the way things were in the dating process, and expressed they were unhappy with it. Men talked about the dating process as choices they had the choice as to what happened next, and this was problematic. Specifically, both men and women talked in ways that enabled me to answer my first research question and take a deeper look in order to analyze the problematic ways they talk through a critical analysis that worked in an effort to answer the second research question.

\section{Critiquing the Ways College Students Talk about Dating, Relationships, and Sex}

\section{Critical Analysis of Women's Language}

Embracing the notion that language creates realities and subjectivities I engaged in a critical analysis of the language used by women to determine how it contributed to particular realties and subject positions that might contribute to rape culture. For women, this included the way they talked about the dating process, the language they used when attempting to empower other women and their inability to engage in comfortable conversations about sex in a straightforward manner revealing particular subjectivities of disempowerment.

First, while the women were not talking directly about men in problematic ways, what emerged from this study was the way their talk positioned them in relation to men in relationships. This study revealed a larger issue of the social construction of women's subjectivities that when habitualized over time to create a sense of normalcy and 
comfortability with disempowerment. Many times, women directly addressed their lack of ability to change the process of dating. Serena described how dating looked and felt to her, and said, "I think that is how dating is even though I would like to see it a different way...I would love to be asked out to happy hour or to dinner but that's just not the way we do things." Her alluding to the inability to change the normalized practice of dating directs attention to the notion that women often find themselves in a position where even the way they describe and submit to the dating process that has been socially constructed for them, positions women within this discourse in particular ways to men. Specifically, that men have the ability to determine where the relationship will go next and thus position themselves without the ability to change things even when it runs counter to their actual desires. When Jenny described how dating looked and felt, she shared, "that's not what I would call dating even though I know that is what it is but it is not what I want to do or how I want to do it." Some of the women felt the casualty of dating applications, traditions of how college students view the pursuit of women, and societal norms, like the rules they described above, led to some of these feelings. Women feeling disempowered was constituted in the language used to talk about dating. Serena added that, "[she] feels like the casualty of it can be such a pro and also such a con because you could just not be into it and leave but that can also happen to you." The fear of being left without explanation or understanding seemed to be more prevalent than the importance of the ability to be able to leave without providing explanation or understanding.

The women in this study wanted to see dating differently, and idealized it in a particular way, but admitted to only pursuing relationships in the way that dating has been normalized and habitualized through social construction within their view of society 
as it is. Often, dating, relationships, and sex perceivably form in linear ways that could be understood through their straightforward description, but for the women in this group, they all admitted to difficulties with the dating process. They admitted that terms used were confusing, and the amount of ambiguity they experienced often led to heartbreak. When Vanessa shared her story of an ideal date that had actually happened, "we arrived at the location where we had horses waiting and we went horseback riding and then he had a sunset picnic ready for us and it was just the most amazing date I had ever been on," the rest of the women quite literally swooned and made comments about it being the perfect date for even themselves, but that this is not typically something they could ask for or expect. They even went into depth explaining that there are norms around even just going to dinner; that can mean so much more than just spending time with someone and it seems like men do not want to do those things (from their perspective). They speculated they may not want to take things too fast, seem like they were too involved in the relationship, or give the women the wrong idea, so they just don't go on the type of dates the women would like to be going on. In all of these instances, the discourse of dating positioned women in a relationship that is dependent upon men, and left them without the power to change the process of dating. In talking about dating in these ways, women participated in a discourse that subjected them to continued practices of dating that were not fulfilling. As such, participation in the idealized discourse of dating women actively accepted that things were the way they were, and continued to habitualized dating norms they don't agree with in the first place.

Second, what emerged as even more problematic was the passive-aggressive ways some women offered validation of women's perspectives on dating yet expressing 
differing values or experiences than others. Sometimes, when women were attempting to validate other women, they were ultimately adding to the marginalization of women. For instance, often, women in the focus groups explained that it was fine for a woman to want casual sex, but then said that they themselves could never do that. In offering this way of talking, the women stated that other women should be able to do whatever they want but that they could never have just a casual relationship or that that they always needed to pursue more than just sex. For instance, Serena attempted to empower other women by saying, “ it just depends on what you want. Some people are just in a phase of their life that they are with different guys every weekend and like sleeping with six of them and that is fine, that's up to them, but my heart could not handle that." Similarly, Blaire said, "I feel like it's honestly hard to get to know people when all you are doing is getting drunk but I don't know maybe it works for them." Women even discussed whether you could actually get to know someone and questioned someone's interest in another individual, if they were dating multiple people or seeing multiple people at once or over a period of time. Georgina said, "I agree that it is good to be able to have options when dating or find someone who has all the things, but when people date around a lot or have a lot of different relationships, I just don't see how you can get connected to that person and I mean more power to you but I wouldn't do it." This way of validating the choices of women, then contradicting the validation results in positioning women in a tensionfilled discourse. Positioning the "right" or "best" way to engage in sexual relationship is if it is in pursuit of the "ideal" or the goal of marriage.

The language used and attitude expressed towards women felt aggressive and lacking in actual understanding that dating, relationships, and sex can be lived out and 
communicated in diverse ways. They would say it was okay for a woman to do something, but the timing of the comment and assertion they used alluded that they did not agree (and sometimes, they outright stated they did not agree). Additionally, the tone and word choices of the women led me to believe they were not okay with how other women they described were acting, and thought they should do things in a different, more normalized or accepted way, positioning women as either conforming to an ideal way of being a woman or violating that norm. Instead of empowering other women to make choices on their own and accept those choices (or validate that those women don't need that acceptance, which acts more as peer approval, in the first place), the specific ways of talking about dating and sex further marginalized women by casting judgement on those decisions and acting as a board to decide how dating, relationships, and sex should look like in those moments.

Finally, the lack of comfort in talking about sex when asked revealed a general limited vocabulary and sense of discomfort when talking about sex. This way of talking resulted in a sense of shame when discussing sex, and a disassociation with their bodies. This way of talking seemed to mean that women either were not given the tools to talk about sex in confident ways, or, that they weren't comfortable enough to engage in discussions about sex as it pertained to dating and relationships. For instance, when asked what sex was, Vanessa simply stated, "P in the V?" while Blaire used the term "base system" to describe different sexual interactions, but mentioned she didn't know if it was still being used since she was not sexually active.

Lack of terminology and the feeling of discomfort in the room when questions about sex were asked, led me to believe that the women felt uncomfortable talking about 
the actual act. And while they said they discussed this with their friends, few of them had actual words to describe the body parts, sensations, and other aspects about sex. This uncertainty reveals a subject positionality that women should not talk directly about the pleasure or joy from sex. This failure to talk directly about sex reveals the way that women are objectified by rape culture disassociate with their bodies, since their bodies have a biological purpose, and that sensuality and pleasure from sex are often not emphasized when students are given tools to discuss sex. The lack of discussion about the pleasures of sex demonstrate this subject position for women. For women, not being able to talk about sex, describe what it should look and feel like for them, can be detrimental and continue to perpetuate rape culture on college campuses in significant ways. If women are positioned within a discourse of dating in such a way as to not have the power to describe their most intimate experiences, what power do they feel they have to describe some of their most invasive or volatile experiences when those happen?

Overall, the language used by women in the focus group discussion exposes how women accepted the "way things are" without feeling like they had the power to change them, and ultimately, submission to male dominance, are the ways this focus group connected everyday talk and language to rape culture. In cultures of sexual violence, the language used to form and influence attitudes towards women is often reciprocated by female counterparts and shows how the dominant culture overtakes these conversations and defines the way things should be done, as well as how things should be talked about. The findings of this study confirm that in everyday talk about relationships dating and sex, women perpetuated the culture that marginalized women. Social history has defined process and order and adhering to that is what women are inherently taught to do in order 
to achieve their goals, which, usually are in alignment with the social norms of dating that have been socially constructed for them as well. In this focus group, I was able to identify that the way women talked about dating, the way they idealized dating, and the position they viewed themselves in relation to men when it came to dating, relationships, and sex was problematic. I also identified that the ways women talked about other women, and the ways they talked about their bodies and sex, are ways that conversations like this one can perpetuate socially constructed views of their subjectivity and perpetuate rape culture on college campuses.

\section{Critical Analysis of Men's Language}

Critically assessing the language used by men in discussing relationships, dating and sex also perpetuated socially constructed norms of dating that contribute to rape culture on college campuses. For men, this way of talking became apparent when it came to their descriptions of dating, that constituted particular dominant power relations among men and women in the dating process and illustrated men's sense of entitlement that stemmed from that power configuration. Additionally, the language used to describe and discuss women that emerged in the focus groups, and specifically when they spoke about rejection and blame, showcased the ways that talking and engaging in conversations with peers has been socially constructed for them to play out in these roles. The way dating, relationships, and sex looks and feels for men, has been habitualized over time to create a sense of normalcy and comfortability within the social culture on college campuses.

Different from women, men felt agency and choice in the dating process. As illustrated in the visual diagram of what dating was like for men, it was less of a series of steps and more of a series of questions. They asked themselves if they liked her, if they 
wanted a relationship with her, and were in control when it came to pursuing a woman and establishing grounds for the relationship, whether it was committed or casual. These options discursively constituted opportunities for men that were not created in the ways women talked about dating. For Chuck, this meant, “devising a plan to get the girl." He explained how he went out of his way to meet people who may know her, to invite her to his house, and to make sure they she would want to come to his house. The language men used to talk about sex positioned them as in pursuit and active in determining what the next step in the process might be. As Chuck indicated, he purposely did not have sex with her initially, so that he could gain her trust and show "difference" than what other men pursuing her might show. While he and the rest of the focus group found this to be a heroic story of the boy chases the girl and ultimately gets the girl, my critical attention to this portion of the focus group arose as an exemplar representation of the ways men showed agency and entitlement within the dating process. He shared how she repeatedly said "no" to coming to his house over a period of time, but he continued to pursue her. When she said "no," he made friends with people she knew and invited them to his house, knowing that she would come. This talk in terms of strategically setting situations reveals the control in the process he seemed to have. And when she finally came to her house, he described the experience of getting her to date him as obtaining a prize. Throughout the story, his explanations reveal that no matter how many times she said "no," he would continue to pursue her. While the men in the room found this heroic, it revealed an unstated assumption that he had the right to pursue sex and demonstrated clear lack of respect for boundaries or the women's stance on their relationship, as he 
ignored her cues and explicit statements of "no" indicating she was not interested in hooking up or dating him.

Similarly, when the group discussed dating applications and the implications of their use it revealed a sense of owning women. For instance, Dan shared, "It feels like you have been presented with a set of gifts, and you get to pick which one you want even though none of them really belong to you or are yours." The way the men even viewed the interactions they had with women on dating applications, showed the entitlement to "what is theirs." This statement from Dan, showed the ways in which men viewed women's place in the realm of dating, relationships, and sex, as without power, choice, or agency. Sharing that they felt they got to pick, and not vice versa, led me to believe they did not value whether or not the women actually picked them. Similarly, sharing that the women were presented to them, as gifts, showed me they viewed them as an object for them to have, that should be presented or given, rather than a reciprocal relationship.

When the men discussed how a relationship becomes more serious, they all shared that they were the ones to ask the woman to become official and described the act of doing so as "noble." While the women shared they would almost never ask where the relationship was going, what they could expect, or where things might go next, the men validated that norm or rule later, when they stated they were always the ones to move the relationship forward and ask what was next, or more so, tell what was next. This way of talking discursively positions men in a position of power as the decision maker where women are positioned as inconsequential or not an equal partner in making these decisions. In this way, the language used to talk about where the relationship goes next reproduces norms of patriarchal structures within dating. Being the one allowed to ask 
questions, the one allowed to ignore 'no,' and the one serving as the sole decision maker, enables power structures that are often found in rape cultures as well. The way they spoke about women and placed their subjectivities below theirs, whether mindfully or not, perpetuated norms of dating that are hurtful and detrimental to marginalized populations.

Looking further into the language used to describe women, it was apparent that the way men talked about women was primarily as sexual beings meant for their own enjoyment and pleasure. If a woman was to disrupt that view, she was name-called, minimized, and objectified. One member of the focus group, Dan, called out another member of the focus group, Bart, for referencing his ex-girlfriend as "a cunt," and, "the most miserable person ever," and for moments there was tension. However, Bart then made excuses for why he did that, and Dan apologized for causing discomfort. While confronting peers can be difficult, this was a clear example of the ways the behavior towards women can be and is validated by other members of male dominated spaces. Dan shared,

I think there are certain expectations for how girls should act. As soon as a girl steps outside of that expectation and if she doesn't treat a guy in a way they want to be treated, like if she ghosted them or treated them in a way they didn't want to be treated, then she is a bitch. It even goes so far that if a guy is doing a group project with a girl who provides leadership or direction, she is a bitch, because they wanted to be the leader. I think this is how guys isolate feelings when they do not feel good about something or if it is threatening. It enables them to cauterize their emotional connection.

This way of talking positions men in control and with the power in situations that make them uncomfortable to end the relationship in ways that are not favorable to them. The group validated this sentiment by discussing that even if a woman doesn't like a man, the men find reasons to name call and shame her, fully aware that they may just not like 
her and that should be okay. The group also identified that the ways they talk when women are around and when women aren't around are very different. Chuck said,

Even you being here, as a women, leading this male focus group, changes things. Men talk about relationships differently, it is more fun and you joke around and you say crude things. You rationalize the hard rejections by name calling...rather than just accepting that she doesn't like you.

Others validated this, but sharing that when they are drinking and hanging out with their groups of guy friends, that is when they most often discuss their relationship and share details they normally wouldn't or even might know that their significant other wouldn't want them to share. Lyle said, "when you're drinking with the boys, the details come out, and you just share a lot of information that you might not normally or that maybe you shouldn't."

For men, these ways of talking about exercising power, exemplifying entitlement, were all clear representations of how dating, relationships, and sex have been socially constructed to allow these power relations to play out and in ways in which the roles to be taken within the social cultures on college campuses privilege men. The ways they discuss dating, relationships, and sex in male dominated space in particular seem to be where a great deal of the validation and justification arise from. Even in this focus group, there were instances when one male called out another male for his behaviors, and those moments all dissolved with justification and explanations that were accepted among the group. The realities and subjectivities formed within this group, and within the everyday talk they exemplified, provided examples of how the language used can be hurtful and perpetuate dating norms that ultimately contribute to the way rape culture is developed and fed on college campuses. 


\section{How Talk Perpetuates Rape Culture on College Campus}

The critical analysis of what women said and what men said within these focus groups, was an important step in this process to answer the second research question, how does the language college students use contribute to rape culture? For these focus groups, several categories arose that created a seemingly negative impact on the culture surrounding dating, relationships, and sex on college campuses. For women, this included the lack of power within the dating process, the language used when attempting to empower other women (but ultimately further marginalizing them), and their inability to discuss sex in a comfortable or detailed way. In sum, the ways women talked about dating and sex positioned themselves within the discourse as in less control of the future of the relationship and dependent upon the choices of men, and shameful about having sex (if it wasn't leading toward the ideal of marriage). For men, the ways they talked about relationships and sex positioned them in control of the ways the dating process unfolded, perpetuated a subjectivity imbued with entitlement and reaffirmed in the language about women that women were objects of desire and pursuit regardless of rejection.

These categories that emerged from this study reveal how everyday talk about relationships, dating, and sex contribute to rape culture because the ways of talking in the focus groups creates and maintains particular realities, and subjectivities in relation to these realities, that maintain the dominance of men in relation to women. The discourse that the women and men used established power relations that positioned women as in less control than men, and as they talked about the realities they described they actively re-constructed normalized ways of relating that align with rape culture. Rape culture 
consists of accepted attitudes about gender and sexuality that normalizes sexual violence against women (Marshall University, 2018). It fosters a culture that accepts the way things are and have been as common sense, and does not allow room for questioning. In this study, women expressed not having the power to change the dating process and for the men this meant allowing their sense of entitlement in the dating process. This everyday way of talking about the dating process allows for environments that play into the power laden structures of rape culture and acceptance of the way things are. When the subjectivities of both men and women are created and those roles of power are able to be played out, rape culture presents itself. The content front the focus groups offered a greater understanding of how those roles look in an actual college culture setting, and how the roles are lived out. It provided context to better understand the ways in which the process of dating and the context of relationships and sex have been socially constructed, and how those three categories play out in the social cultures on college campuses. 


\section{CHAPTER FIVE: DISSCUSSION}

This study explored the subtle and taken-for-granted ways college students talk that create certain realities positioning them with certain subjectivities. The findings of this study reveal how the particular ways of talking about dating, relationships, and sex contribute to problematic systems of meaning for women on college campuses. While these problematic ways of talking may not have been intentional, their impact is significant and perpetuates rape culture on college campuses, reproducing and reenabling systems of power. Specifically, the ways that the process of dating was discussed by women and men creates and maintains specific relations of power among women and men. What was most revealing is that the language used by both women and men resulted in the marginalization of women. For instance, the inability for women to comfortably discuss sex in terms of what it looks like, means, and feels like for them, are all ways this study identified perpetuation of rape culture within the context of the conducted focus groups. In this section I discuss the findings of the study in relation to social construction theory and research focused on language, power and subjectivity. Further, I offer implications of the findings of this study for those interested in addressing the complex issue of rape culture on college campuses. In particulars, the findings of this study provide insights into how it is possible to make a difference in the problems facing women on college campuses by changing the everyday ways students talk about dating, relationships, and sex. 
The findings of this study support the notion that language socially constructs reality. Specifically, this study reveals how everyday talk and language is problematic in the ways that it contributes to rape culture on college campuses. The way that language shapes meanings about gender, and generates relations of power among women and men in the dating process, to the disadvantage of women, is detrimental as it reifies norms and values that are hurtful for women. These processual norms of dating and ways of talking about relationships and sex exposed in this study demonstrate how particular concepts have been habituated and generated relational roles are assumed and played out by actors in relation to one another (Berger \& Luckmann, 1966). These concerns about the ways in which young people on college campuses are talking about dating, stem from the idea that the way in which they are talking is producing and enabling social systems that are ultimately power laden and generative of marginalizing subjectivities. The ways of talking act as concepts and representations of behaviors that, when repeated over time, create larger systems of meaning (Berger \& Luckmann, 1966). For example, the roles assumed by men and women in the dating process are simply the result of habits and behavioral norms that have been socially constructed (Berger \& Luckmann, 1966). This study reveals how language contributes to the institutionalization of the dating process, and exposes how "the way things are," is accepted as truth, and influences how individuals participate within that system, and within a (rape) culture, and come to know themselves as participates in this process. Habitualization can tell us that these habits and behavioral norms are more detrimental than we may think. For example, the women in this study expressed frustrations with feeling a lack of power to change the systems of dating. Yet they do not demonstrate much resistance to these meanings. They 
overwhelmingly seemed to accept the process of dating as "just the way things are," and they talked about following the rules and expectations that have been established in social practice. Further, as they expressed the rules and expectations of dating they continued to reify these practices. Even the practice of men shaming and name-calling women who did not align within their expectations or desires becomes part of the normal process of dating. Overall, the findings of this study contribute to social construction theory by demonstrating how everyday talk about dating is habitual and institutionalizes particular realities about relationships and sex among college students.

Furthermore, the findings of this study offer an example of how everyday language is political as they reveal how language constitutes relations of power positioning women in the process of dating in limiting ways, and continuing a patriarchal way of understanding of how dating works that reinforces and reifies the power laden norms that marginalize women. As stated earlier, this study is deeply rooted in the understanding that an individual's self is constructed through language (Larson \& Gill, 2007). As dating, relationships, and sex become habitualized and institutionalized through the processes of social construction, this study reveals that these ways of talking are political, because they are rooted in social practices that generate power relations and forms of subjectivity that disadvantage and marginalize women (Weedon, 1987). In other words, the findings of this study demonstrate how patriarchy has been (re)created through habitualization and institutionalization of the practice of dating that positions women in a lesser relation to men through everyday language. What is most striking about this study is how women, actively recreated these institutionalized norms and subject positions. For instance, in the instances in which women attempted to empower other women by 
validating their own decision making, the words they used and the comparisons they offered when discussing these choices, acted to constitute subjectivities and exercise social control (Weedon, 1987). This way of looking at politics within discursive practices aids to the claim that everyday experiences, or language, is political it produces and reproduces particular institutional practices that advantage some and disadvantage others (Deetz, 1992).

Specifically, the findings of this study show how everyday language generated particular ways of knowing women and men in the process of dating. Here, women's subjectivity positions them in a submissive place below men and men's subjectivity positions them in a dominant place over women. When women and men participate in the discourse of dating, they assume these positions without always knowing it, and certainly without reflecting on the impacts the subject positions they embrace in the larger picture of rape culture. For instance, when one of the participants in the focus group shared how he continually, "did not take no for an answer," when pursuing a women for a relationship, it is likely he did not know the link that could be made to in the ways in which the choice and agency women have in sexual interactions can be stifled. This study reveals how language like this, is what generates normalized practices that can lead to sexual assault commonly occurring. When everyday language institutionalized ways of being that limit, stifle, or ignore the voices of women, women's subjectivities are defined for them without their agency and choice. In this way the everyday language about dating creates the ways in which women view the world, and view their place within the world (Weedon, 1987). For instance, when the men in this study talked about the pursuit of a partner as a noble endeavor, the language used to talk about dating in this way was 
actually a practice of power as it positioned men as "pursuer" and women as "the object of pursuit" which contributes to the ways women and men view or understand their subjectivity in the dating process. Because this way of talking was seen as normal and even a "good way" of dating among the participants of the study it demonstrates the taken for granted and normalized quality of this language. It is in this way that this study contributes to research on language, power and subjectivity.

Finally, this study has meaningful implications for those interested in the issues related to rape culture on college campuses. Specifically, this study reveals the importance of exploring the language and discourse about dating, relationships, and sex and evaluating how taken-for-granted ways of talking can be problematic. As this study shows, it is important to identify how terms, processes, and behavioral norms work in oppressive ways. In particular this study reveals how language can generate relations of power among women and men that position men as having more options than women and reestablish ways of knowing women as objects for men's pursuit. The ways people use language in everyday life create meaning, and ultimately construct ways of understanding themselves and their position in the world. Unfortunately, for many, these meanings limit the possibility for action and position their ways of being in ways that normalize being "lesser than" others. As this study shows, the choice in how to shift the culture trickles down to a choice in how women and men talk about the process of dating, sex, and relationships how they see themselves and others in this process. While it can be easy to lose hope in changing this large system meaning there is hope that that small changes in the ways women and men talk about dating can de-normalize rape culture and though 
finding alternative ways of talking about dating can generate relationships among women and men in the dating process that are more empowering for women.

\section{Recommendations}

As I conducted research, and reflected back on my 20-year-old self who thought she had agency and freedom over her sexuality, I realized I was just a pawn in a larger game to these men. As this study shows, I actively participated in maintaining rape culture. This study helps reveal how individuals' bodies and subjectivities are constituted by the words and actions among both women and men that perpetuate rape culture by offering tacit approval that this way of understanding dating, relationships, and sex is 'okay.' I thought of my friends, my sisters, and my community. When college students are talking about these behavioral norms as appropriate and normal, these ways of talking perpetuate the problems. I am left wondering when women (including myself) begin to accept this language about dating, and how can we find ways to change the language in ways that no longer perpetuate rape culture.

As I write my recommendations for change, I hit a crossroads. Do I speak to the women who have been marginalized by the language perpetuating this vicious culture? Do I speak to the men who "should have known better," but continue to talk about women in objectifying ways? Or do I speak to parents, siblings, peers, friends, teachers, professors, administrators of higher education and others with opportunities to step in and initiate better ways of talking about dating and sex? Individuals learn this sense of validation in the language they use from the people who have the most influence over them, and that is how we can make change. If these problems stem from subtle, everyday 
ways of talking, then the ways to initiate change must arise in altering the subtle, everyday ways of talking.

Embracing Weedon's (1987) notion of critical practice, I believe that addressing the problems associated with the language of dating and sex begin with assessing how power structures are formed and how they produce and reproduce power relations. With this understanding, those interested in making change need to identify sites within discourse that allow for an opportunity to subvert the discourse (and thus, power relations constituted in the discourse). In challenging taken-for-granted ways of talking and challenging world views and power structures in place, we can begin creating new realities through conversations that generate alternative relations of power and subjectivities. By changing our language we can stop accepting the taken for granted because, 'this is how they have always been,' and we start questioning the ways in which things are done. As Weedon (1987) explains, common sense is how power is maintained. Thus, by changing the everyday ways we talk about relationships, dating, and sex we can disrupt what is common and generate new meanings together. In other words, by intervening on the common, everyday language that perpetuates rape culture, we can end the subtle and taken for granted ways that position some individuals with more power than others, and generate environments on college campuses that are safer for women. As such, this study makes a call for parents, siblings, peers, friends, teachers, professors, administrator of higher education to get involved in paying attention to how dating is talked about by young people, and get involved in those conversations in ways that do not replicate the taken-for-granted practices of dating, but offer opportunities for women and 
men to reconstruct the dating process in ways that redefines subject positions and leads to a healthier culture about relationships and sex on college campuses.

My call to parents, siblings, peers, friends, teachers, professors, administrators of higher education, means calling to them to take on the responsibility that could change the discourse and create new realities for younger generations. I imagine it means, looking at your son when he calls his sister names and having the conversation as to why that is not okay. I imagine it would look like talking to your younger sibling about how to ask questions about dating, relationships, and sex, and how to talk about those things in healthy ways. I imagine and hope, that it would mean teachers, professors, and administrators of higher education having crucial conversations in their workplaces to implement stronger sex education, that includes how to talk about dating, relationships, and sex, how to offer support and seek resources, and how to create safe spaces where these conversations can bloom.

In order to do this, parents, siblings, peers, friends, teachers, professors, and administrators may integrate several changes into their own language and discourse when attempting to create safe spaces for conversations. First, they may begin by being mindful and understanding how they, themselves, play into the discourse and systems at play (Allen, 2011). This is important when attempting to subvert oppressive or marginalizing ideologies because when individuals are able to recognize how their own thoughts are perpetuated by dominant discourse, they can be mindful of their own actions and in turn, lead by example (Allen, 2011). Second, they can be proactive in their language by focusing on power and privilege, as well as continuing learning about the experiences of others through their own research (Allen, 2011). Knowing their own power and privilege 
is important in understanding what areas they have influence in. It is important to note that not all individuals are privileged with an ability to speak out, and this could be for a number of reasons. If they are, however, able to do so safely, they can become ready to respond to behaviors and comments that are harmful within groups of friends and peers. They can also learn to be proactive in conversations rather than reactive, teaching or offering information before the dominant discourse can present itself. It is also important to note that they can do a lot by simply taking on the task to educate themselves. It is not the responsibility of the marginalized or oppressed to explain who they are and how that positions them within the world. When someone feels compelled to share their experiences and stories, be sure to listen but always know this is not their job. Finally, individuals can take these two tasks and build on them with communication tools that allow expansion of safe spaces for this discourse (Allen, 2011). If they can find the language and words that will enable others to understand how these thoughts are socially constructed and how they play into these roles, they will be able to open conversations up with more accessibility. If an individual is not understanding the points that are attempting to be made, explain how their privilege places them in a position (if it does) to allow them to do this research on their own. Encourage individuals to advocate for their own learning and growth. Remind them of the recommendations above as well - they should be mindful, they should be proactive, and they should learn about social identity issues on their own rather than placing this job on those who already feel the harmful or negative pressures of their subjectivity.

My hope and vision for this research, is opening the door to more conversations about how we talk about dating, relationships, and sex in problematic ways and what we 
can do to subvert the discourse. Through discursive openings, we can create change within the systematic ways of talking that are inherently power laden, creating these realities and subjectivities that are ultimately harmful for our friends, sisters, and communities. For instance, when a friend shares her experiences of sexual assault, look to offer words of support rather than words of blame. Similarly, when you hear peers discussing a woman as a 'slut' or 'bitch' because they were simply not interested in dating them, intervene and educate them on the impact of those words on the individual. In one of the all-male focus groups, I had one individual speak to the group towards the end about the ways so much of what they said was problematic or harmful. To many, this had never even been addressed and it certainly appeared to be eye opening for them. In another instance, I challenged one of the participants views in asking how they would feel in the situation if the roles had been reversed with the woman they were seeing. The group laughed and commented, "she is calling you out Nate." But for Nate, he shared this was the first time he had thought about how the situation may have made him feel and the first time he was able to reflect or attempt to understand how the woman may have felt. To be silent is to face contempt and acceptance of, 'the way things are' (Lorde, 1984), and I hope that this paper serves as an example as to how contempt within our language and discourse can be detrimental.

In this study, I was able to look at the everyday language that perpetuates cultures of sexual violence. Through focus groups, qualitative analysis, and critical analysis, I was able to identify the ways in which this commonly happens and discuss motives for change. The repetition of hurtful comments can be detrimental to an individual, and the 
reproduction of power that allows individuals to put out those marginalizing comments is very apparent on college campuses.

While I answered my research questions, describing the ways that college students talk about sex and relationships in hurtful ways and explaining how this language perpetuates rape culture, this study left me with some open-ended questions and observations that would be helpful for any researcher entering into this field to pay careful attention to. This study exploring how women and men talk about dating was conducted with too simple conception of gender. Specifically, by limiting my study to women and men, I perpetuated a discourse that gender is binary, and it is not. As a researcher attempting to change the discourse around dating, relationships, and sex, it was incredibly difficult to find my study contributing to ways of understanding sex and gender in binary terms. I was confronted with a few potential participants of this study who did not feel comfortable being separated into a focus group of "women" or of "men" and this was especially painful when I was interested in exploring issues of oppression in an attempt to educate on the oppression of another.

As such, for those who will continue to engage in this type of research, exploring how language perpetuates rape culture in ways that affects a broader spectrum of individuals, I recommend finding ways to examine language without the presumption of gender in binary terms. While this study looked at the ways dominant discourse is oppressive towards women, it left out an entire population of individuals who are also oppressed by dominant discourse. Similarly, I want to reify the implicit heteronormativity in this study. The ways in which gender was separated based on binary, aided in perpetuating the ways participants may have shared their experiences in particularly 
heteronormative ways. The ways in which the groups talked about dating, relationships, and sex perpetuated norms within those contexts. Gender and sexuality are not binary, and should not be seen as a one-size-fits all when it comes to studies like these. It is important to be thoughtful and critically assess the ways in which your research might further work to oppress marginalized populations, and I would like to see further work done to look at the ways in which language aids as a source of oppression when it comes to how we talk about dating, relationships, and sex on college campuses, and perpetuates rape culture. Overall, however, I hope this study contributes to a better understanding of how language perpetuates rape culture and offers those who read it to recognize the ways their everyday language might perpetuate rape culture and inspires change by reconsidering the everyday ways they talk about relationships, dating, and sex. 


\section{REFERENCES}

Allen, B.J. (2011). Difference matters: Communicating social identity. Long Grove, IL: Waveland Press, INC.

Barnett, M.D., Hale, T.M., \& Sligar, K.B. (2017). Masculinity, femininity, sexual dysfunction beliefs, and rape myth acceptance among heterosexual college men and women. Sexuality \& Culture, 21, 741-753.

Berger, P.L., and Luckmann, T. (1966). The Social Construction of Reality: a Treatise in the Sociology of Knowledge. Anchor Books.

Burch, F.G., Batchelor, J.H., Burch, J.J., Gibson, S., \& Kimball, B. (2018).

Microaggression, anxiety, trigger warnings, emotional reasoning, mental filtering, and intellectual homogeneity on campus: A study of what students think. Journal of Education for Business, 93 (5), 233-241.

Crime in the United States (2013). Rape. U.S. Department of Justice: Federal Bureau of Investigation. Retrieved from https://ucr.fbi.gov/crime-in-the-u.s/2013/crime-inthe-u.s.-2013/violent-crime/rape

Deetz, S. (1992). Democracy in an age of corporate colonization: Developments in communication and the politics of everyday life. Albany: State University of New York.

Fedina, L., Holmes, J. L., \& Backes, B. L. (2018). Campus Sexual Assault: A Systematic Review of Prevalence Research From 2000 to 2015. Trauma, Violence, \& Abuse, 19(1), 76-93. https://doi.org/10.1177/1524838016631129

Fey, K.E. \& Medway, F.J. (2006). An acquaintance rape education program for students transitioning to high school. Sex Education, 6 (3), 223-236. 
Harris, K.L. (2011). The next problem with the no name: The politics and pragmatics of the word rape. Women's Studies in Communication, 34, 42-63.

Haugen, A.D., Rieck, S.M., Salter, P.S. \& Phillips, N.L.. (2017). What makes it rape? A lay theories approach to defining rape among college students. Basic and Applied Social Psychology, 40 (1), 18-35.

Larson, G. \& Gill, R. (2007). Organizations and Identity. Polity.

Lee, J., Pomeroy, E. C., Yoo, S.-K., \& Rheinboldt, K. T. (2005). Attitudes Toward Rape: A Comparison Between Asian and Caucasian College Students. Violence Against Women, 11(2), 177-196. https://doi.org/10.1177/1077801204271663

Lindlof, T. R., \& Taylor, B. C. (2011). Qualitative communication research methods. Thousand Oaks, CA: SAGE Publications.

Lorde, A. (1984). Sister outsider. S.1.: Penguin Books.

Marshall University (2018). Rape Culture. Marshall University: Women’s Center.

Retrieved from https://www.marshall.edu/wcenter/sexual-assault/rape-culture/

McMahon, S. (2010). Rapy myth beliefs and bystander attitudes among incoming college students. Journal of American College Health, 59 (1), 3-11.

Phipps, A., Ringrose, J., Renold, E., \& Jackson, C. (2018). Rape culture, lad culture, and everyday sexism: Researching, conceptualizing, and politicizing new mediations of gender and sexual violence. Journal of Gender Studies, 27(1), 1-8.

Powers, R.A., Leili, J., Hagman, B., \& Cohn, A. (2015). The impact of college education on rape myth acceptance, alcohol expectancies, and bystander attitudes. Deviant Behavior,36,956-973.

Reling, T.T., Barton, S.B., Becker, S., \& Valasik, M.A. (2017). Rape myths and hookup culture: An exploratory study of U.S. college students' perceptions. Sex Roles, 78(7-8), 501-514.

Singh, S., Orwat, J., \& Grossman, S. (2011). A protection motivation theory application to date rape education. Psychology, Health, and Medicine, 16(6), 727-735. 
Tracy, S.J. (2013). Qualitative research methods. UK: Blackwell Publishing.

Wiersma-Mosley, J.D., Jozkowski, K.N., and Martinez, T. (2016). An empirical investigation of campus demographics and reported rapes. Journal of American College Health, 65(7), 482-491.

Weedon, C. (1987). Feminist practice and poststructuralist theory. Oxford: Blackwell. 